\title{
Preliminary Design Report
}

Solid

Waste

Operations

Complex W-113 


\section{Preliminary Design Drawings}

\section{DISCLAIMER}

This report was prepared as an account of work sponsored by an agency of the United States Government. Neither the United States Government nor any agency thereof, nor any of their employees, makes any warranty, express or implied, or assumes any legal liability or responsibility for the accuracy, completeness, or usefulness of any information, apparatus, product, or process disclosed, or represents that its use would not infringe privately owned rights. Reference herein to any specific commercial product, process, or service by trade name, trademark, manufacturer, or otherwise does not necessarily constitute or imply its endorsement, recommendation, or favoring by the United States Government or any agency thereof. The views and opinions of authors expressed herein do not necessarily state or reflect those of the United States Government or any agency thereof.
Prepared for

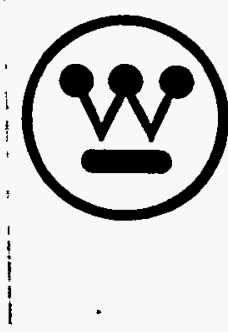

Westinghouse Hanford Company

Prepared by

Rajitineon Engineers \& Constructors 


\section{DISCLAIMER}

Portions of this document may be illegible in electronic image products. Images are produced from the best available original document. 


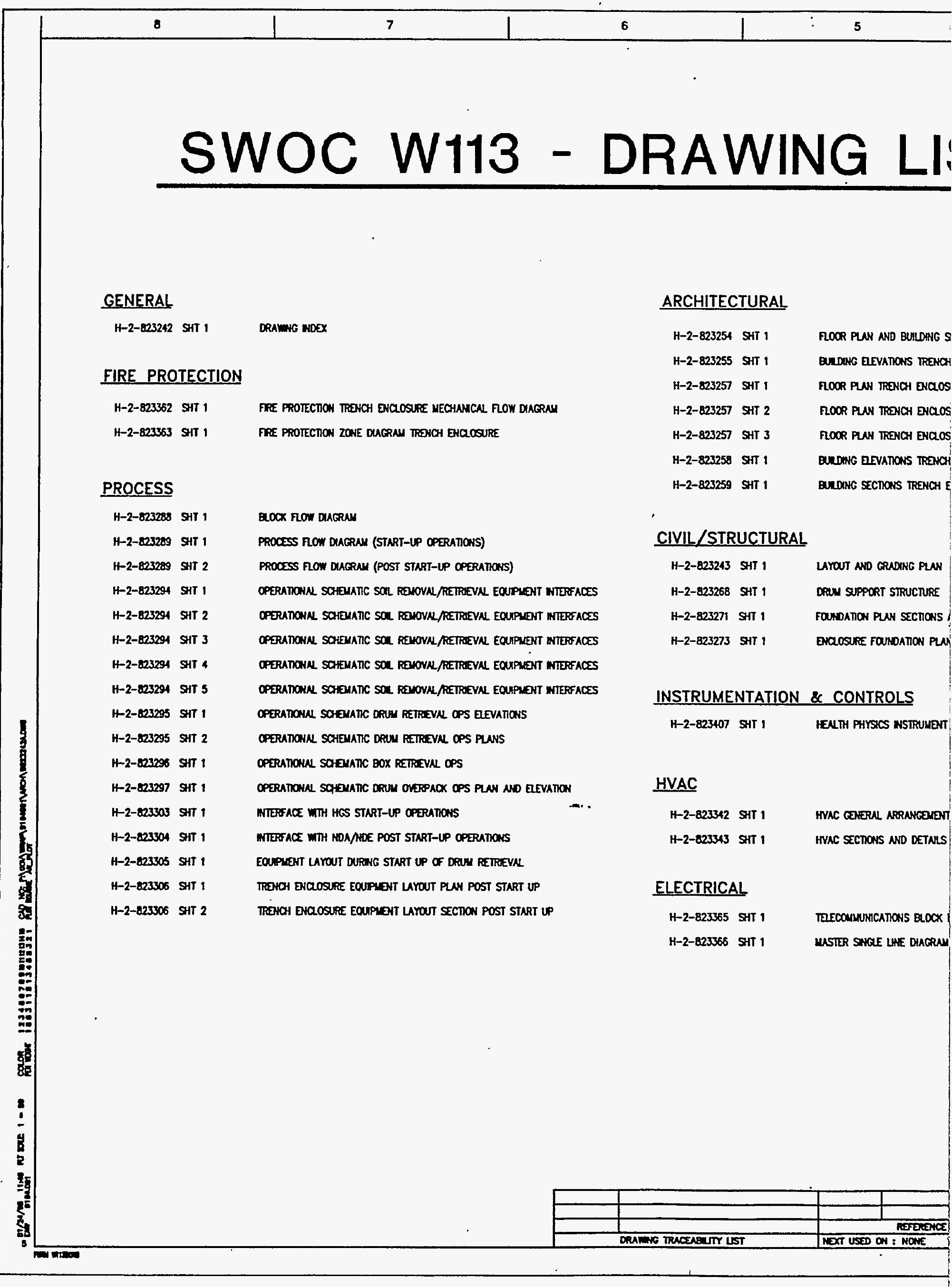




4

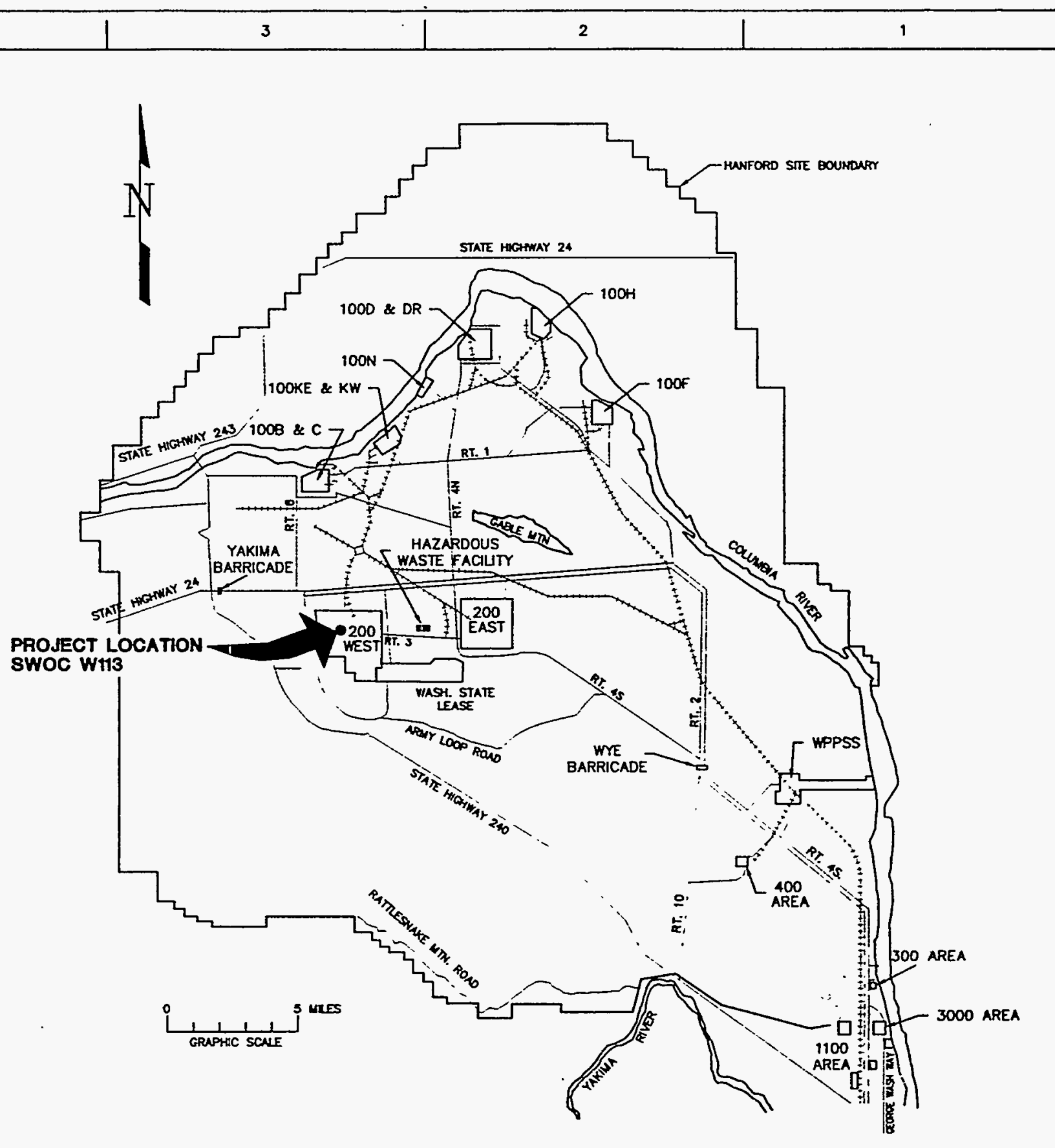

OWS TREMCH OPERATIOH

gRATON

FRST POSTION

secand POSTION

THRD POSTION

aOSURE

OSURE

DETARS

ctow

ATON PUN TRENCH EROLOSURE

D EQUPUENT SCHEDULS

VICINITY MAP

SCNE: $r=3$ MILS

I DIAGRM

Baybhoom

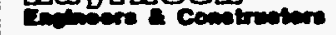

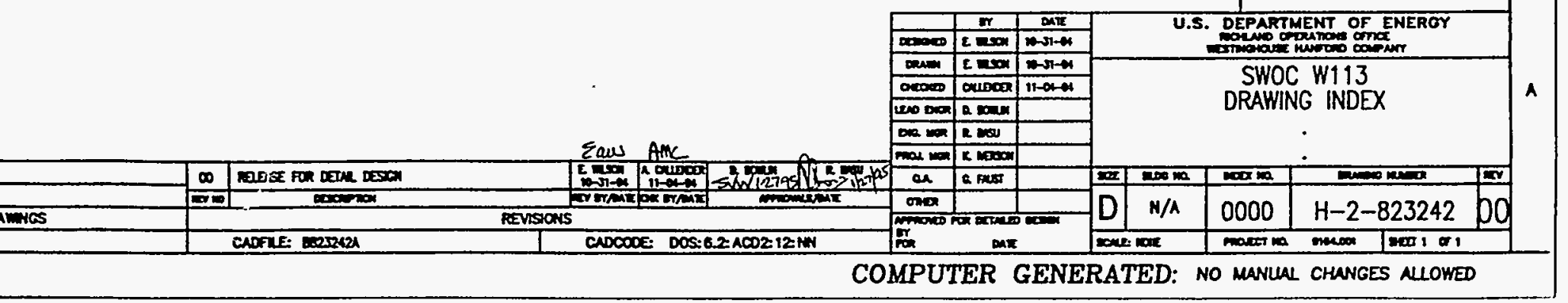




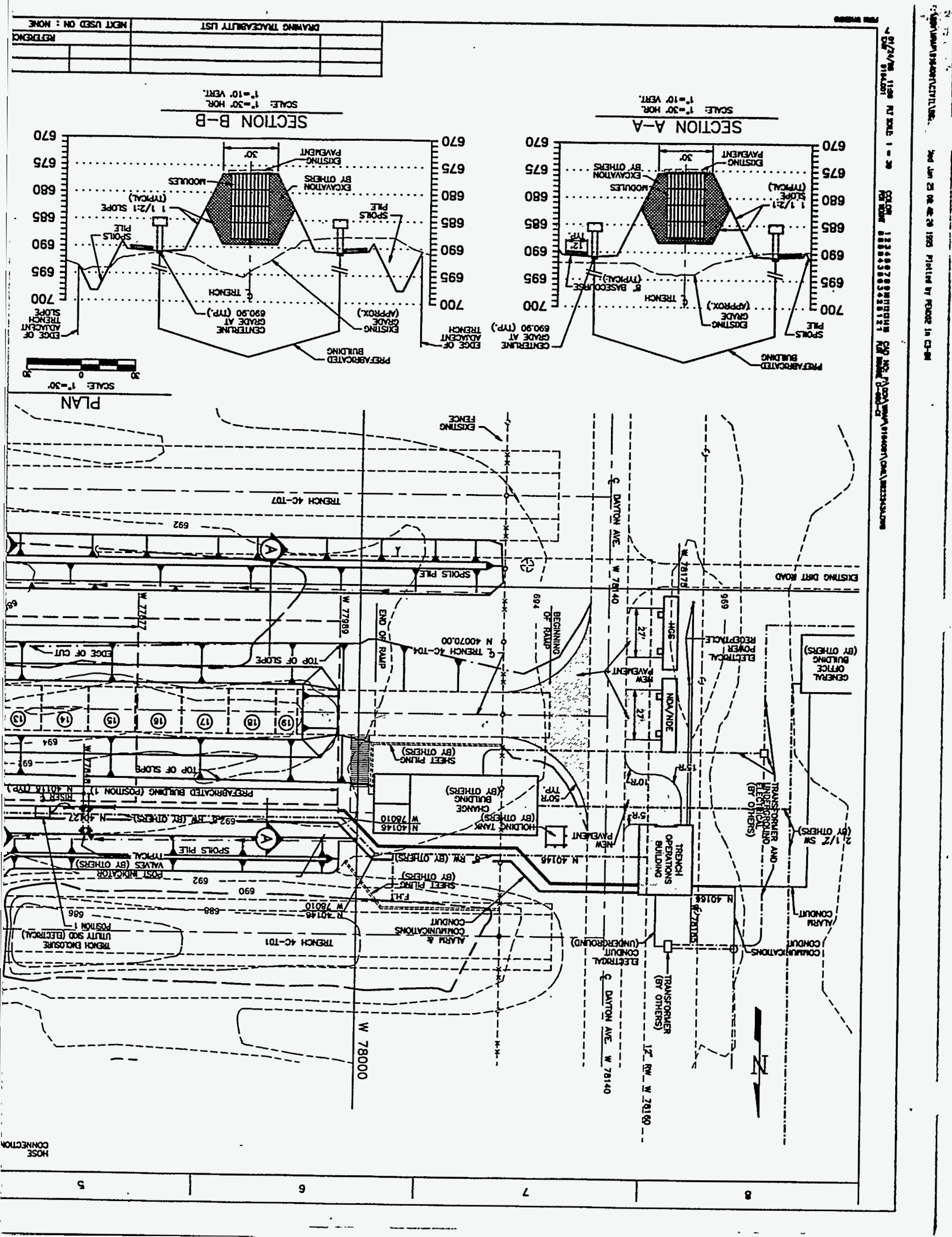




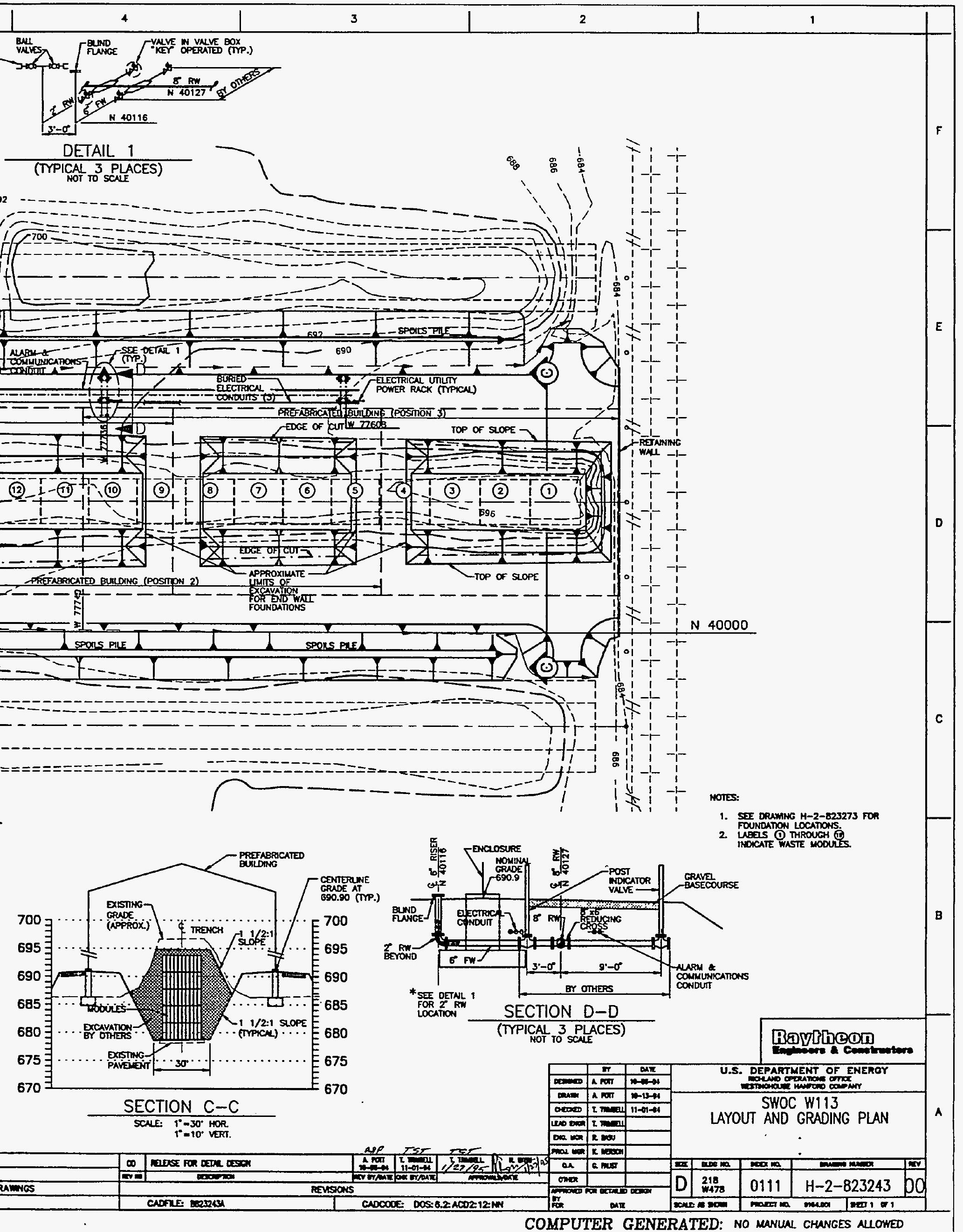




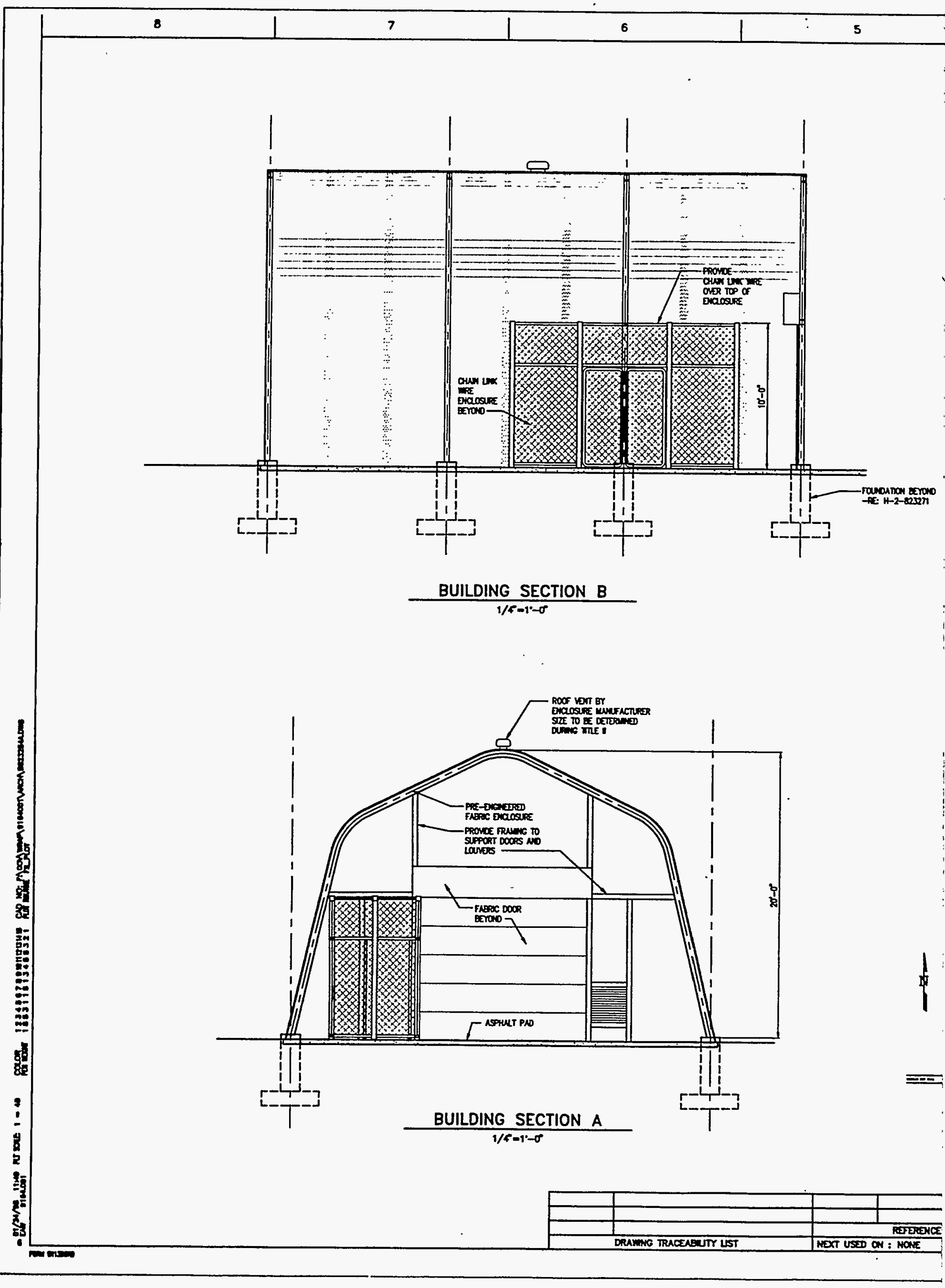




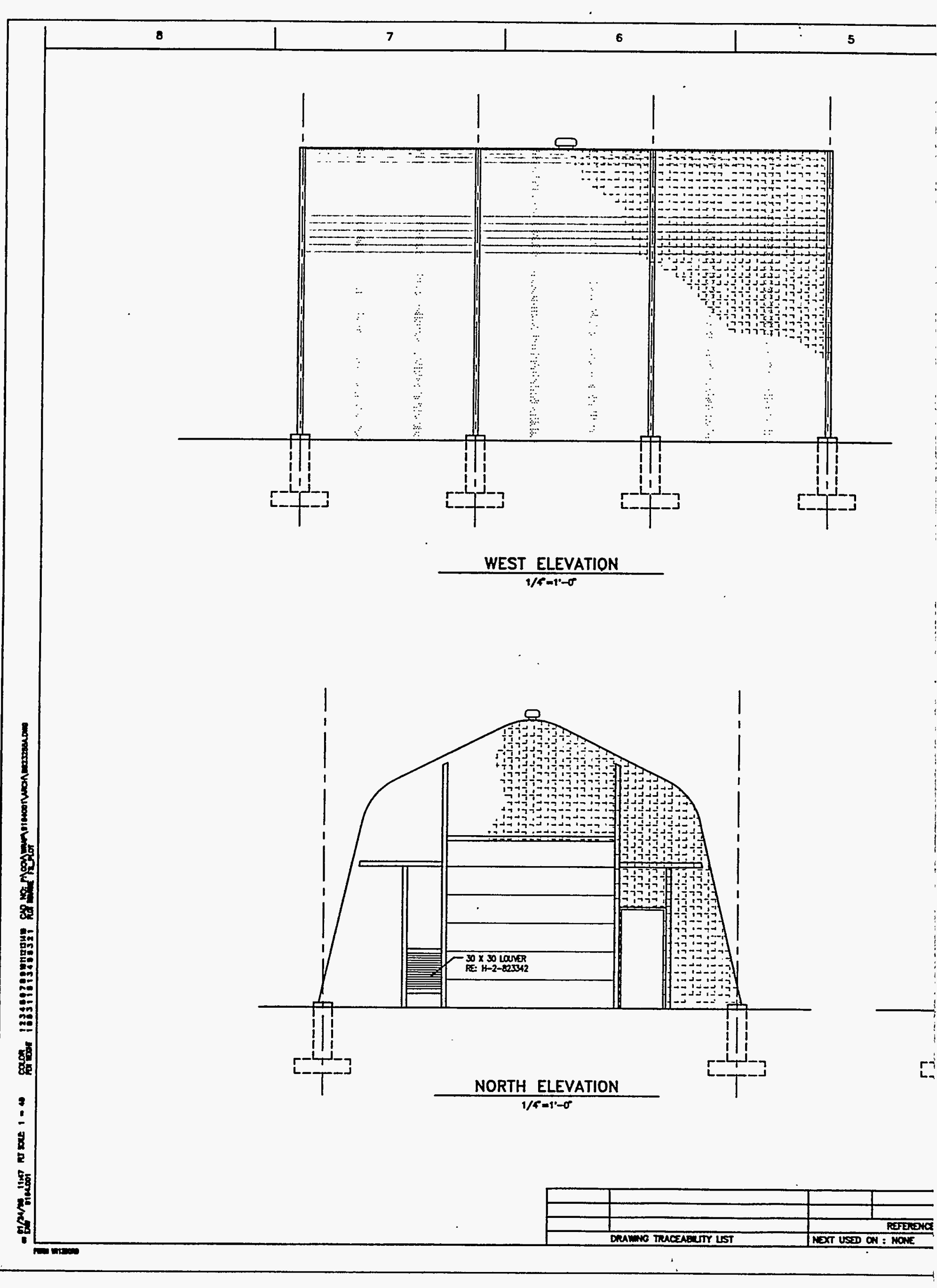




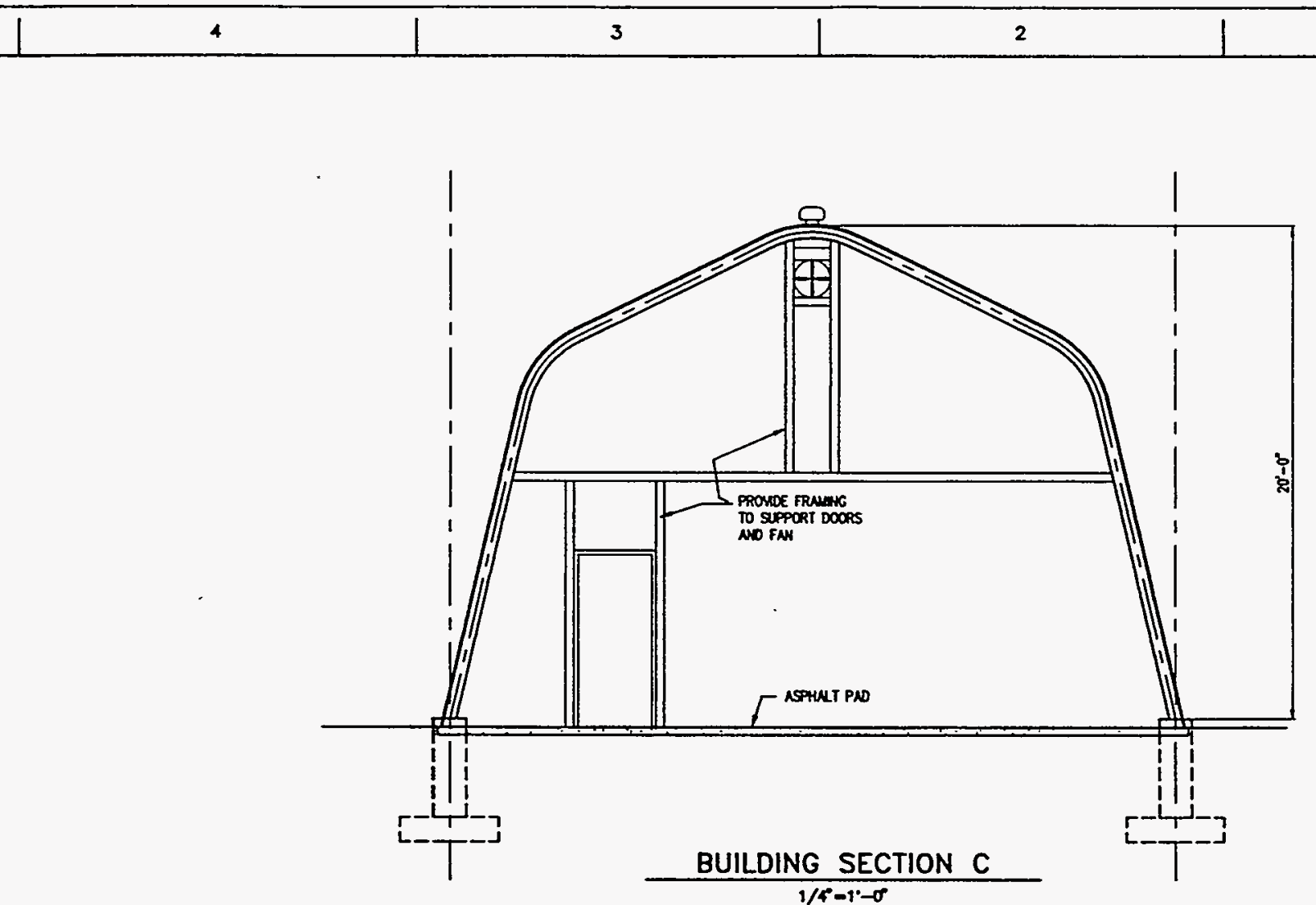
$1 / f=1 \cdot \sigma$

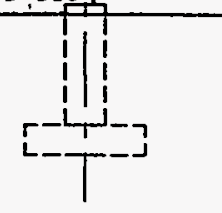

BaybLoOn Endere a cometruotere 


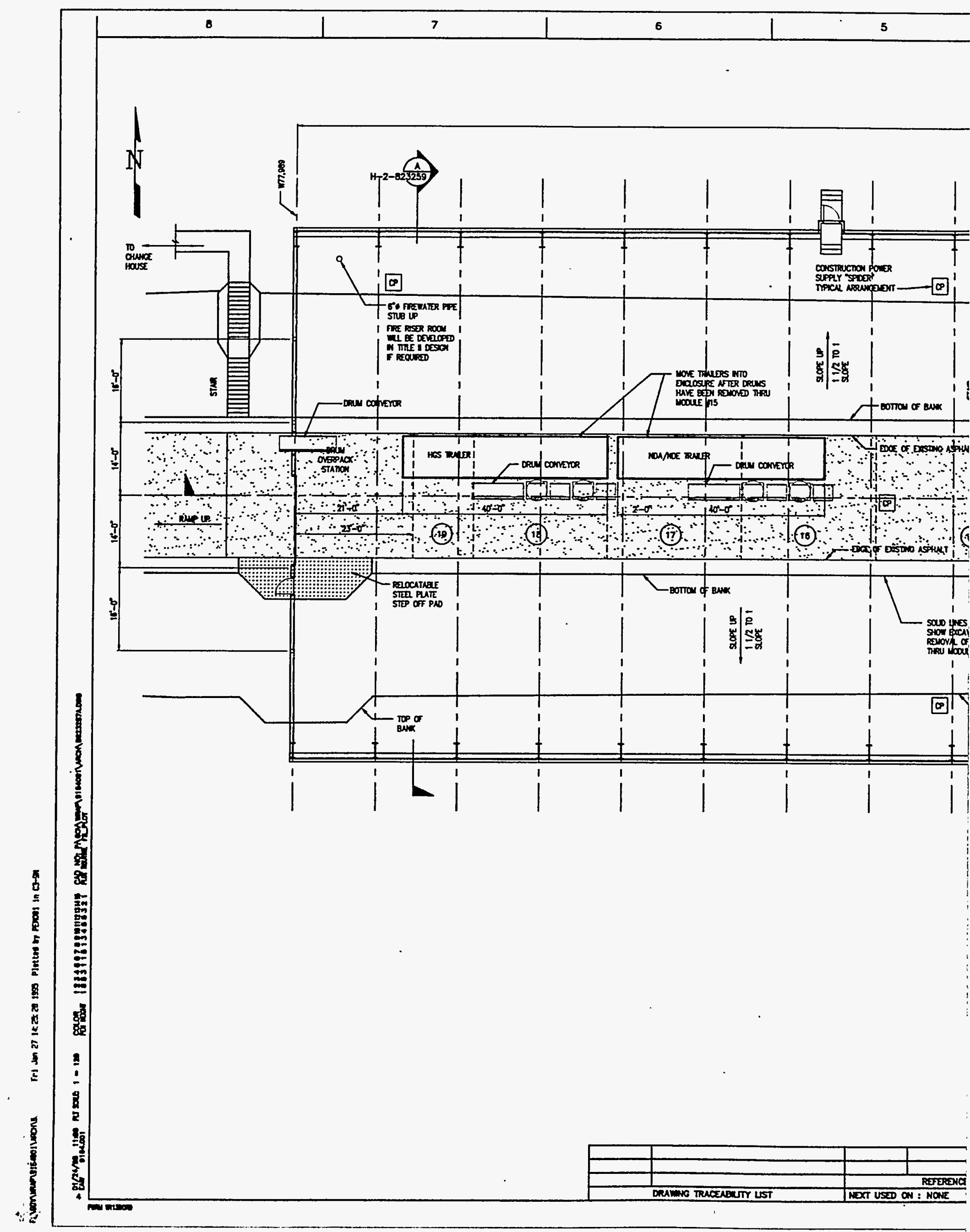



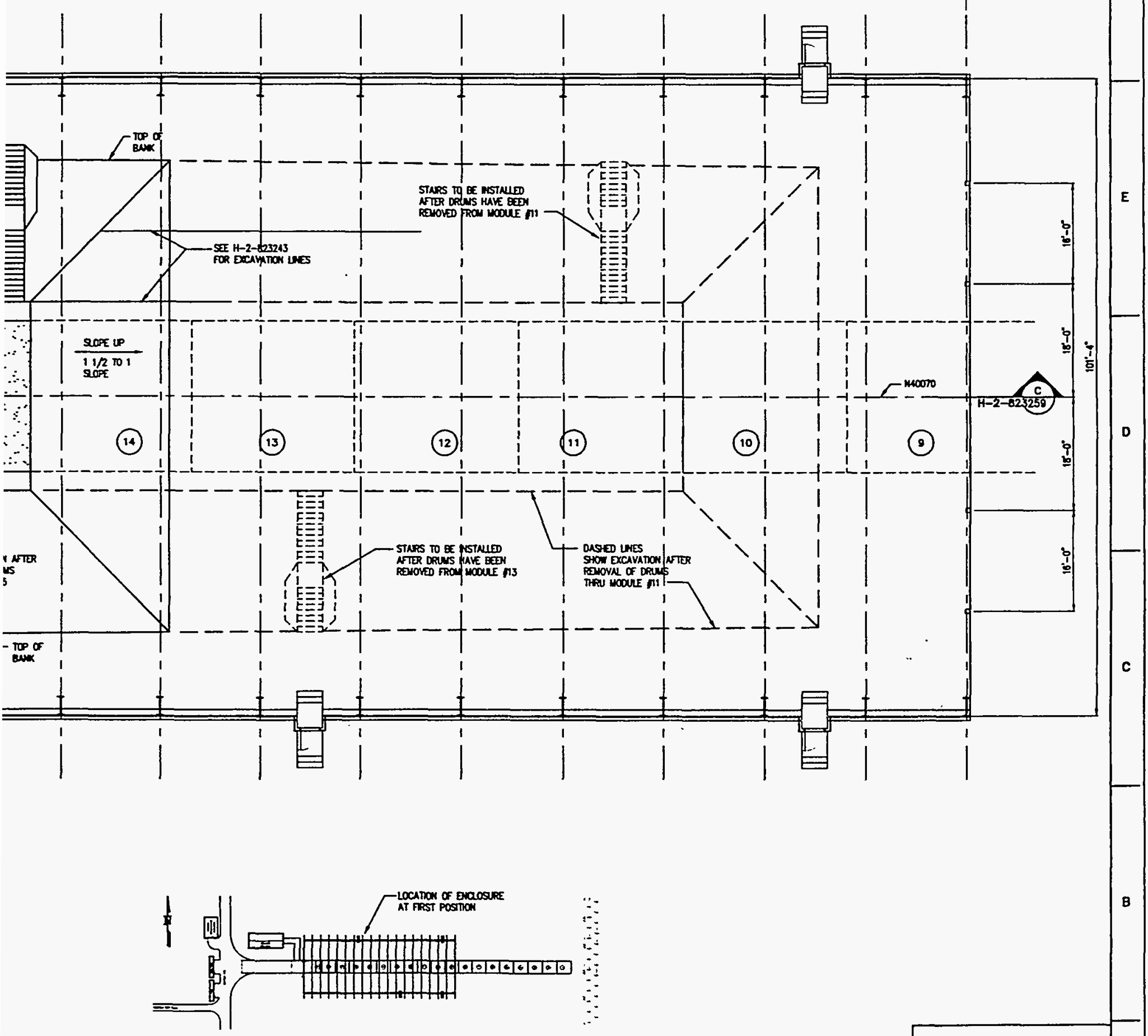

KEYPLAN

\begin{tabular}{|c|c|c|c|c|c|c|c|}
\hline & & & & & \multicolumn{2}{|c|}{ BDPCLBOD } & \multirow{9}{*}{ A } \\
\hline \begin{tabular}{|l|l|} 
& 0 \\
\end{tabular} & \begin{tabular}{|l|} 
or \\
$\operatorname{armen}$ \\
\end{tabular} & $\frac{\cos x}{\operatorname{lng} x-4}$ & \multicolumn{4}{|c|}{ 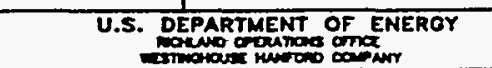 } & \\
\hline$=$ & \begin{tabular}{|l|l|} 
ould \\
\end{tabular} & $\frac{0-50-\alpha}{10-4}$ & \multirow{4}{*}{\multicolumn{4}{|c|}{$\begin{array}{l}\text { SWOC W113 } \\
\text { FLOOR PLAN } \\
\text { TRENCH ENCLOSURE } \\
\text { FIRST POSITION }\end{array}$}} & \\
\hline we Dom & $2 \cos x$ & & & & & & \\
\hline 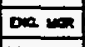 & 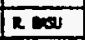 & & & & & & \\
\hline man man & 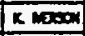 & & & & & & \\
\hline$\omega_{\mu}$ & & & a & $\infty$ & $\cos 12$ & 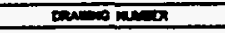 & \\
\hline ond & 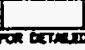 & 50 & $D$ & $\begin{array}{l}218 \\
\text { m47 }\end{array}$ & 0800 & $\mathrm{H}-2-823257$ & \\
\hline & an & & & 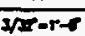 & maxt & 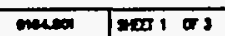 & \\
\hline
\end{tabular}




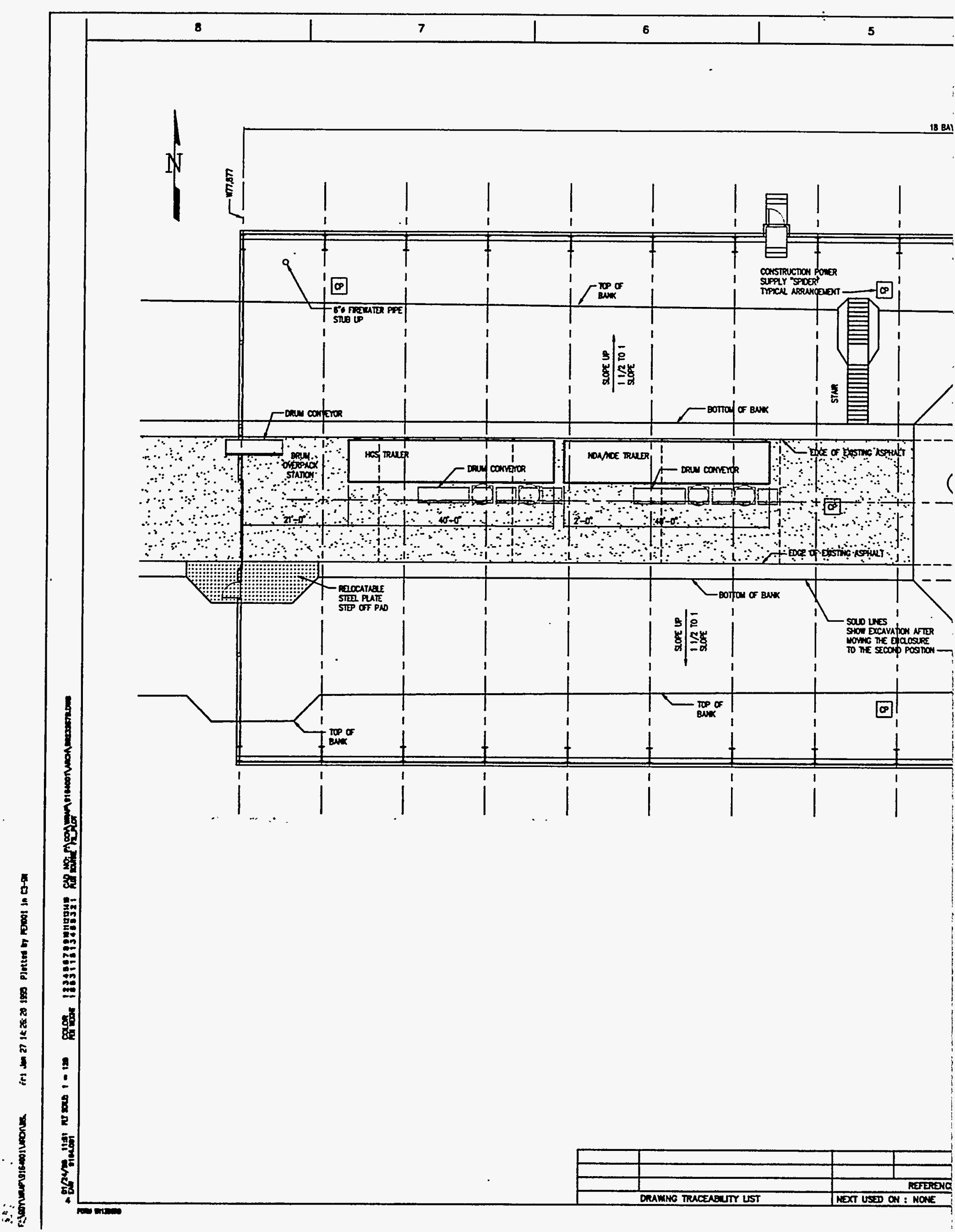




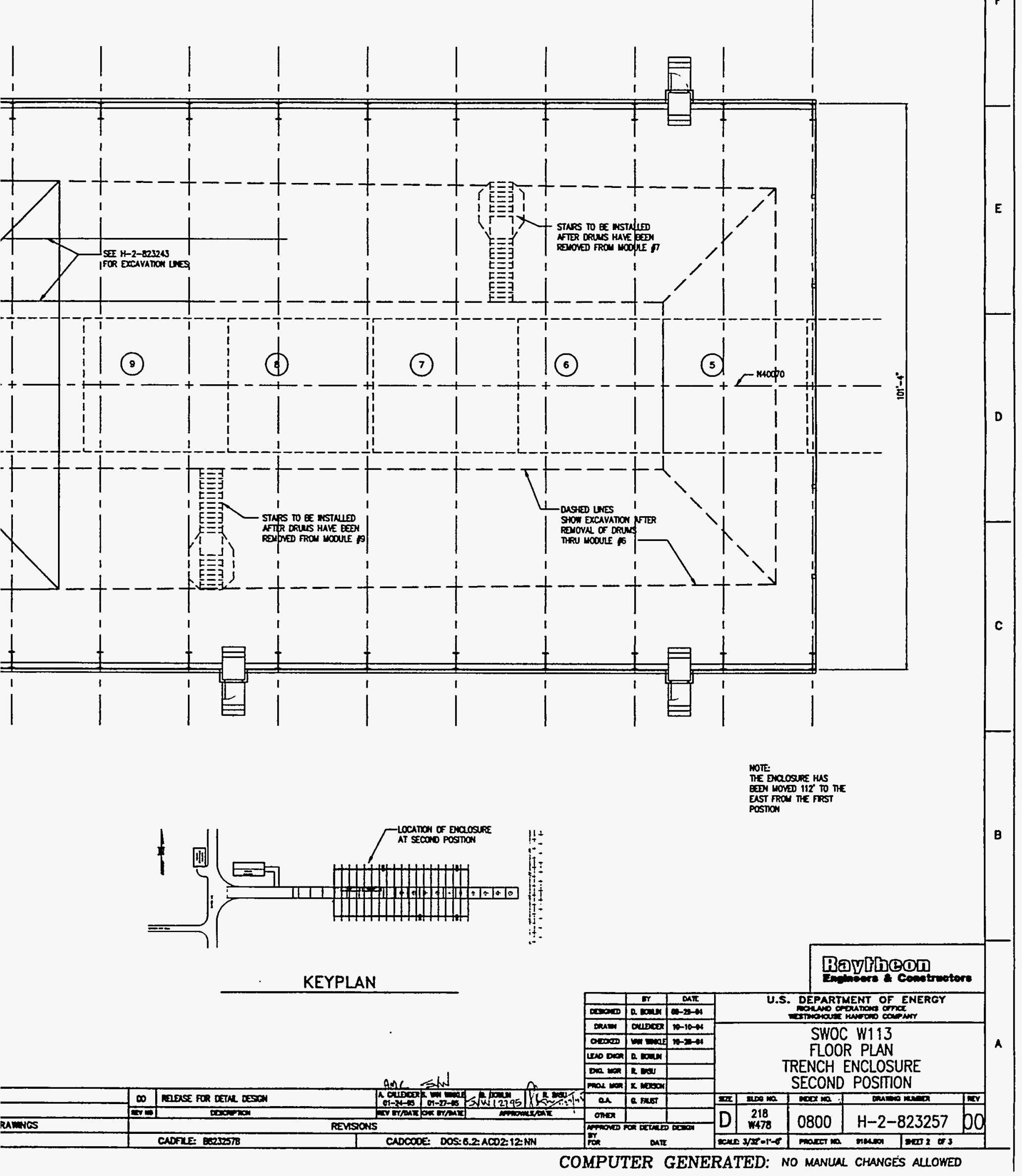




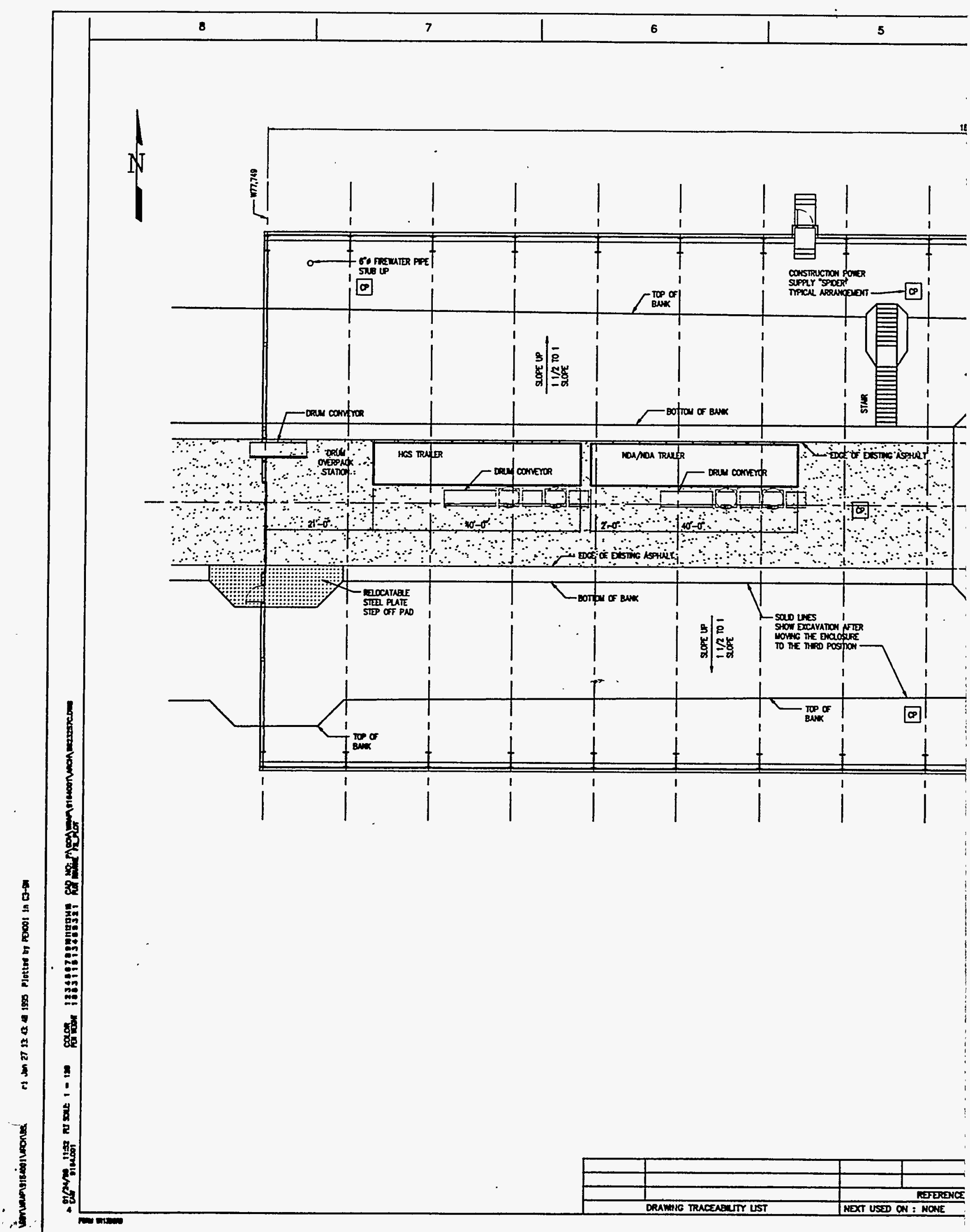




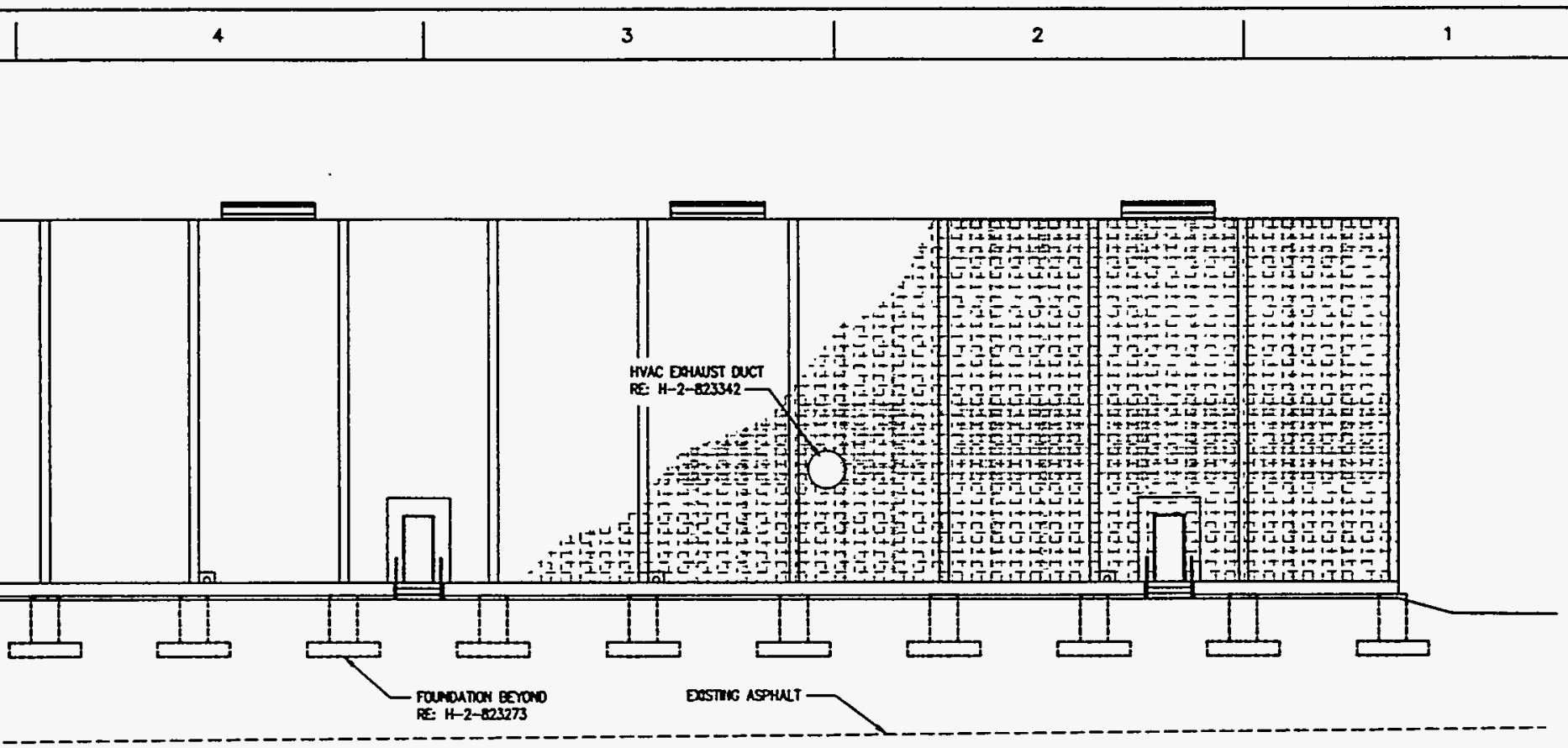

F

E

D

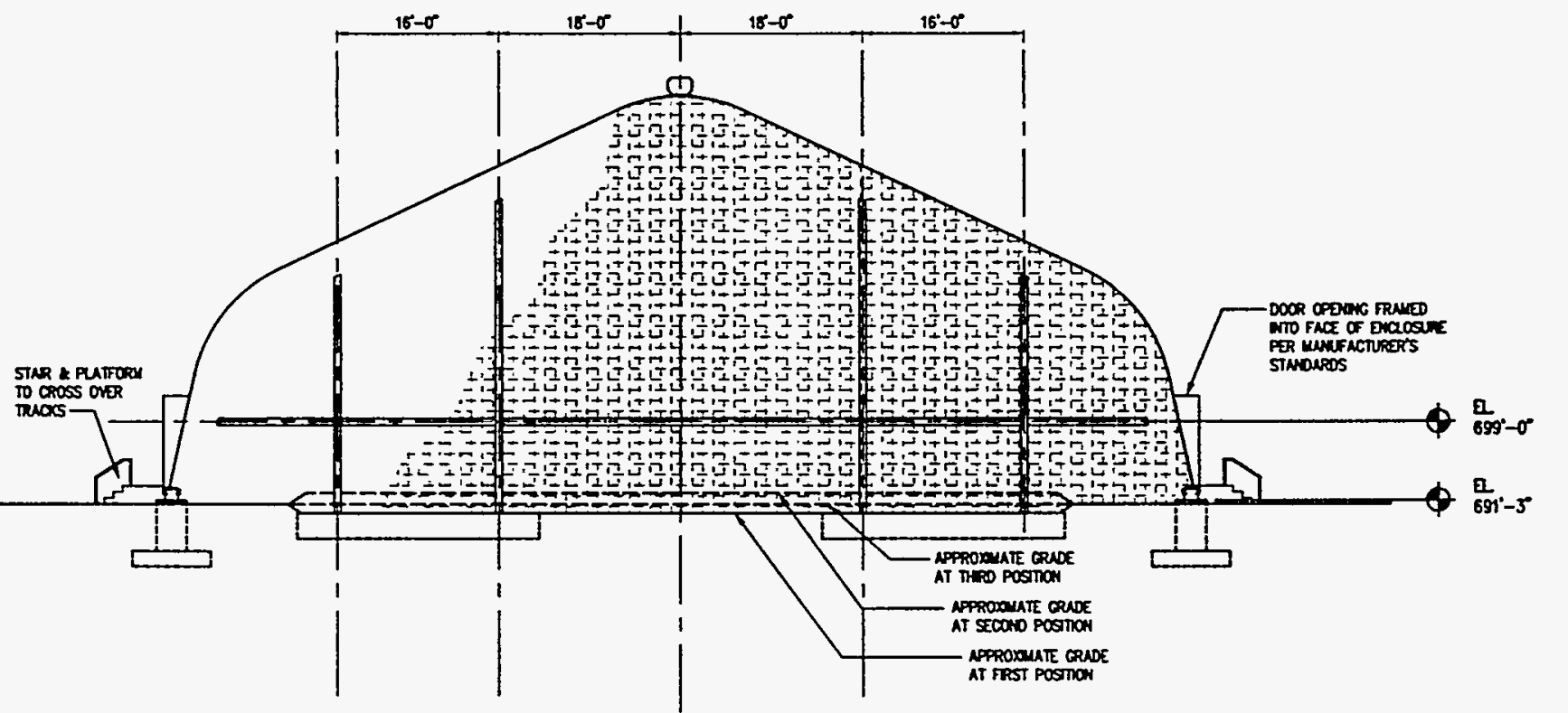

\& TRENCH DOA

EAST ELEVATION

N THE FRST POSTION

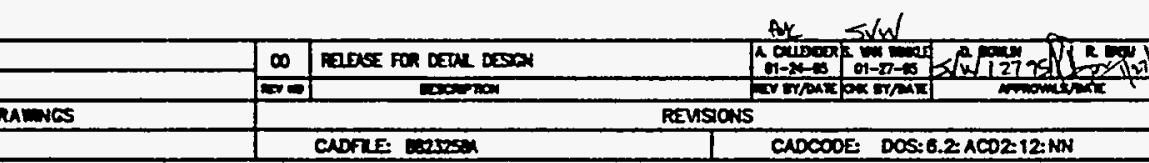

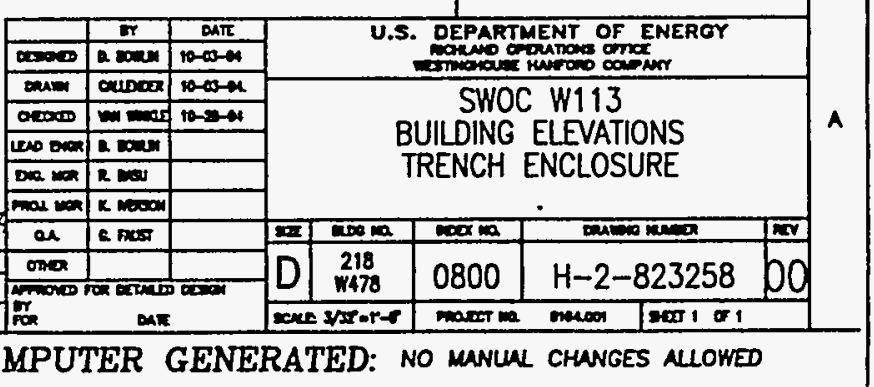




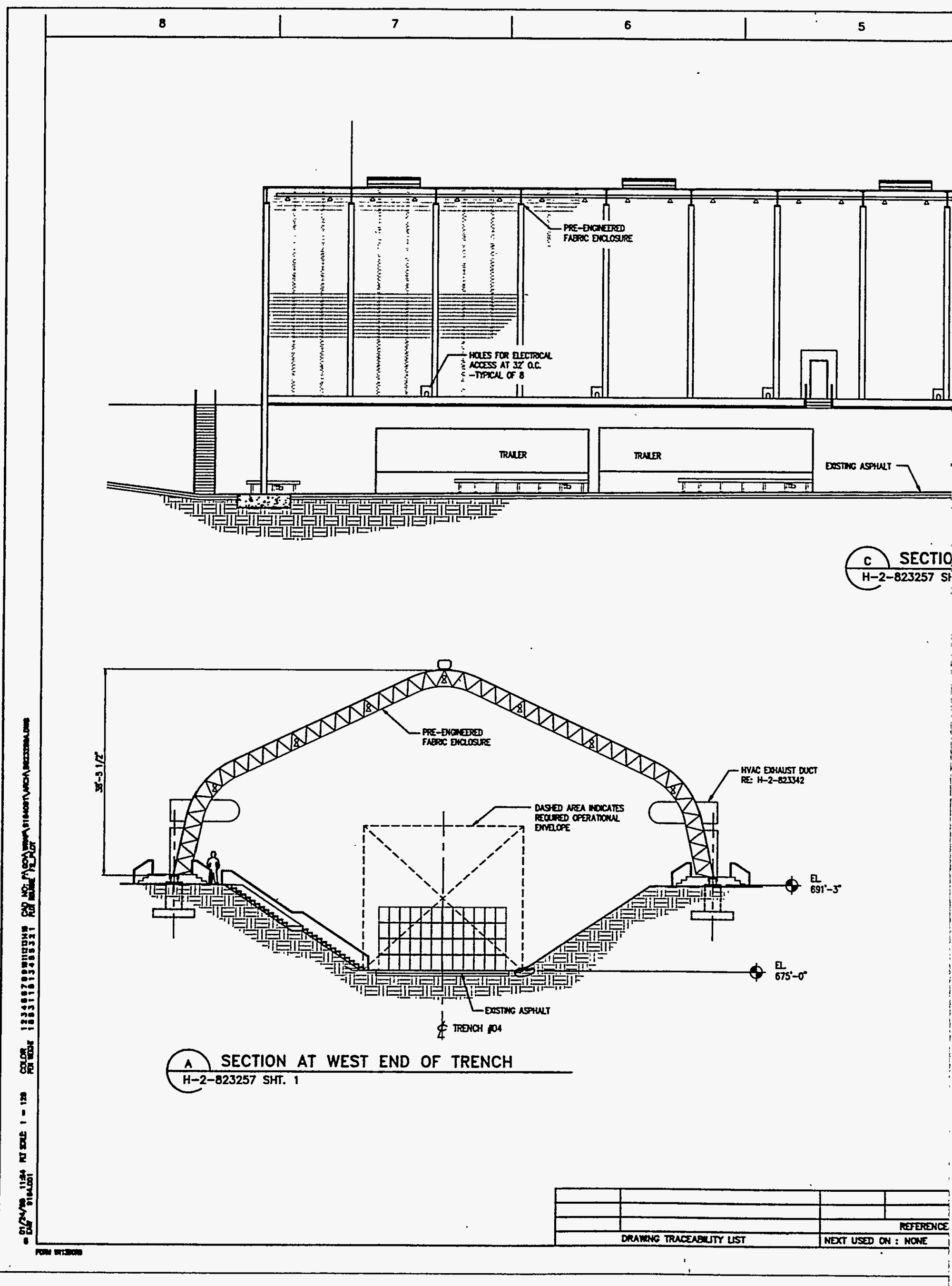



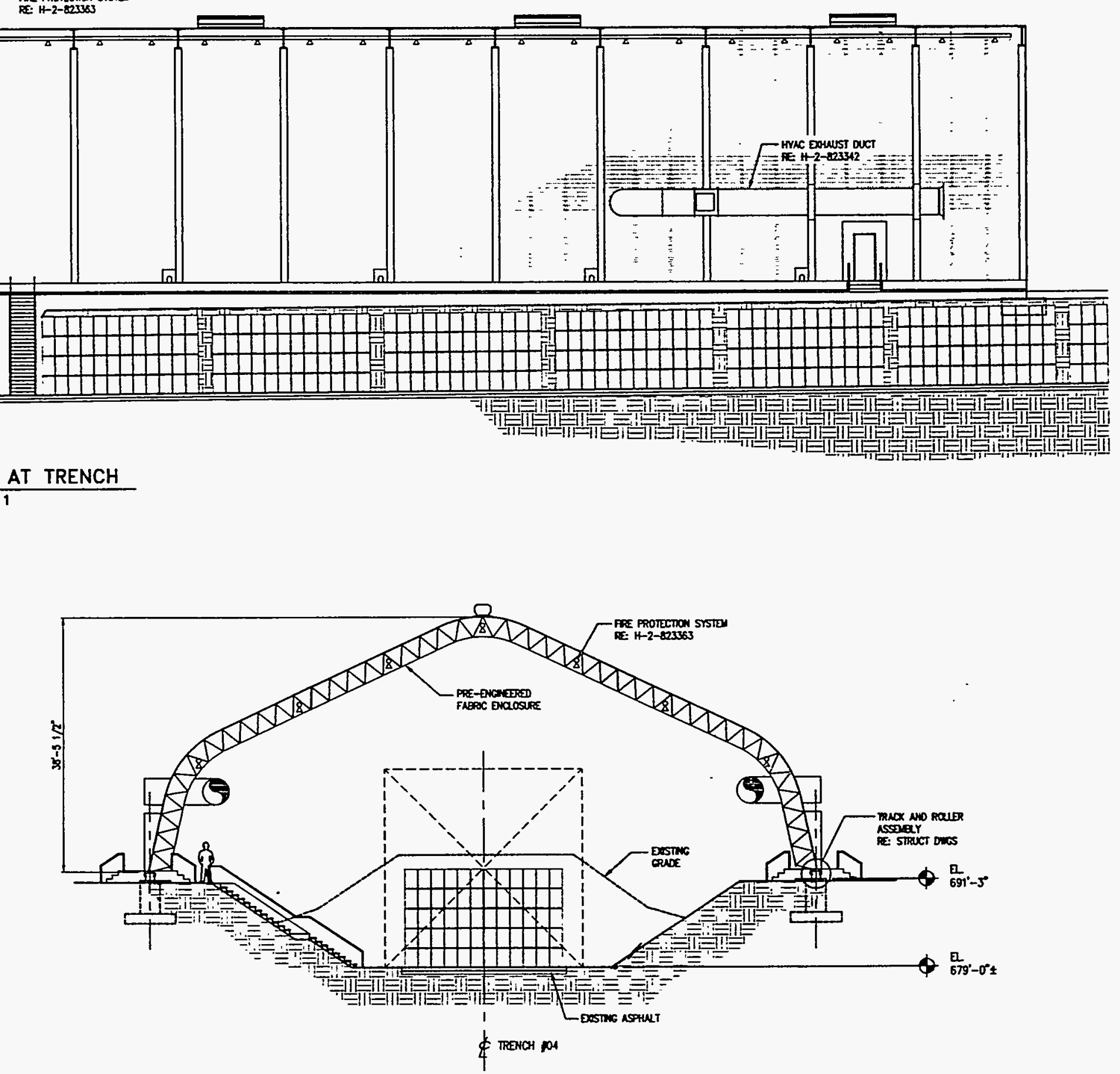

8 SECTION AT EAST END OF TRENCH H-2-823257 SHT. 3

\begin{tabular}{|c|c|c|c|c|c|c|c|c|}
\hline & & & & & \multicolumn{3}{|c|}{ BaVSLBOD } & \multirow{9}{*}{$\mathbf{A}$} \\
\hline - & $\frac{\pi}{2 \min }$ & $\frac{\sin \pi}{0-2 \pi-\infty}$ & \multicolumn{5}{|c|}{$\begin{array}{l}\text { U.S. DEPARTMENT OF ENERGY } \\
\text { OF }\end{array}$} & \\
\hline \begin{tabular}{|l} 
oum \\
000000
\end{tabular} & ouroese & $0-2-n$ & \multirow{4}{*}{\multicolumn{4}{|c|}{$\begin{array}{c}\text { SWOC W113 } \\
\text { BUILDING SECTIONS } \\
\text { TRENCH ENCLOSURE }\end{array}$}} & & \\
\hline \begin{tabular}{|l}
000000 \\
1000
\end{tabular} & 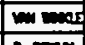 & $x-2-4$ & & & & & & \\
\hline \begin{tabular}{|l|l|}
100 & 00 \\
000
\end{tabular} & $2 \cos x$ & & & & & & & \\
\hline ma & $\frac{x+\infty}{x \cos x}$ & & & & & & & \\
\hline an & a favos & & 亚 & 000 & $\cos m a$ & 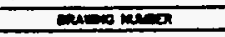 & Wy & \\
\hline $\operatorname{mon}$ & & 1 & $D$ & $\begin{array}{l}218 \\
m 478\end{array}$ & 0801 & $H-2-823259$ & Do & \\
\hline 恧 & ox & & sent & $\sqrt[3 / 2 x-t-6]{2}$ & $\operatorname{man} x$ & menom $\mid=x 1$ का & & \\
\hline
\end{tabular}




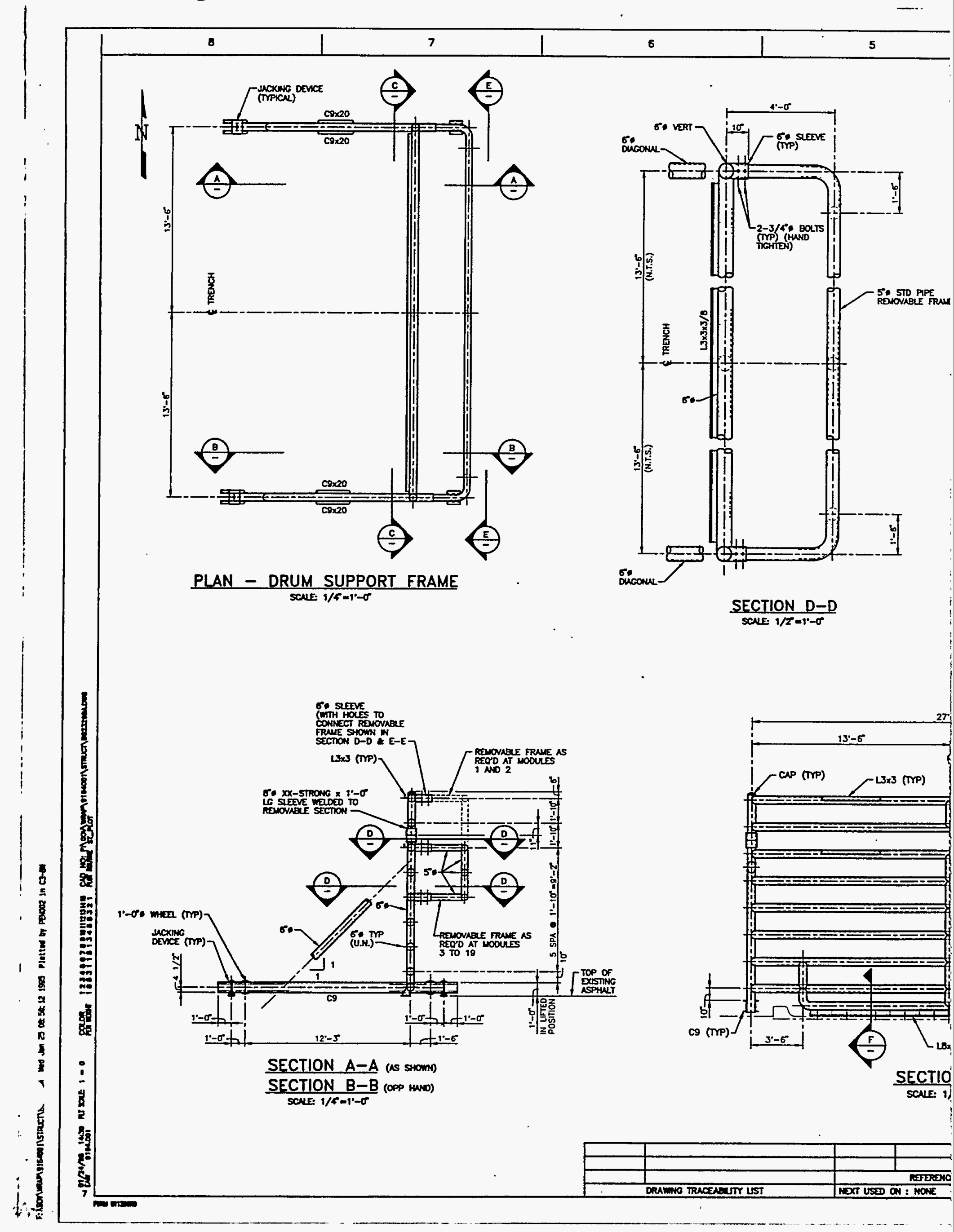



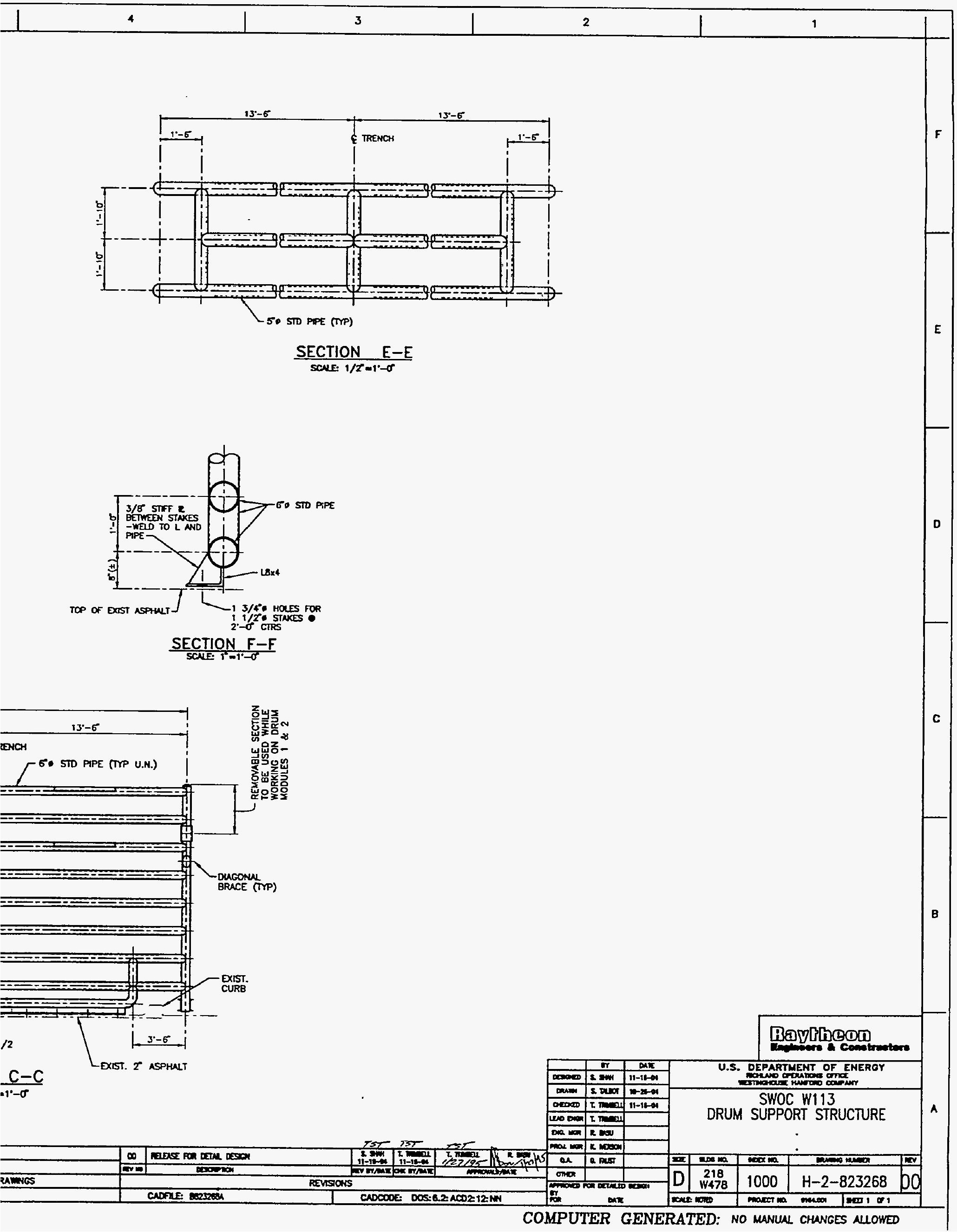


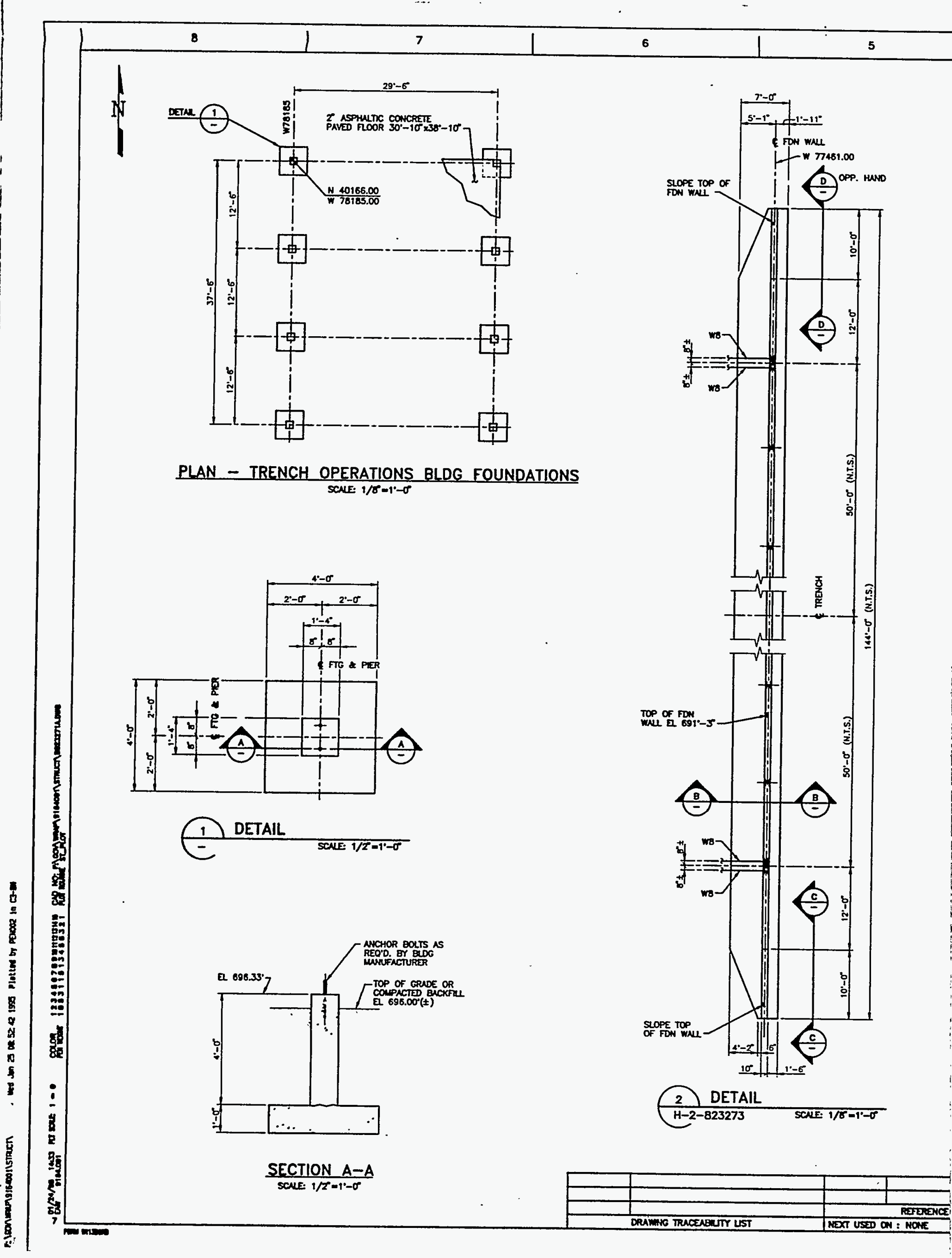




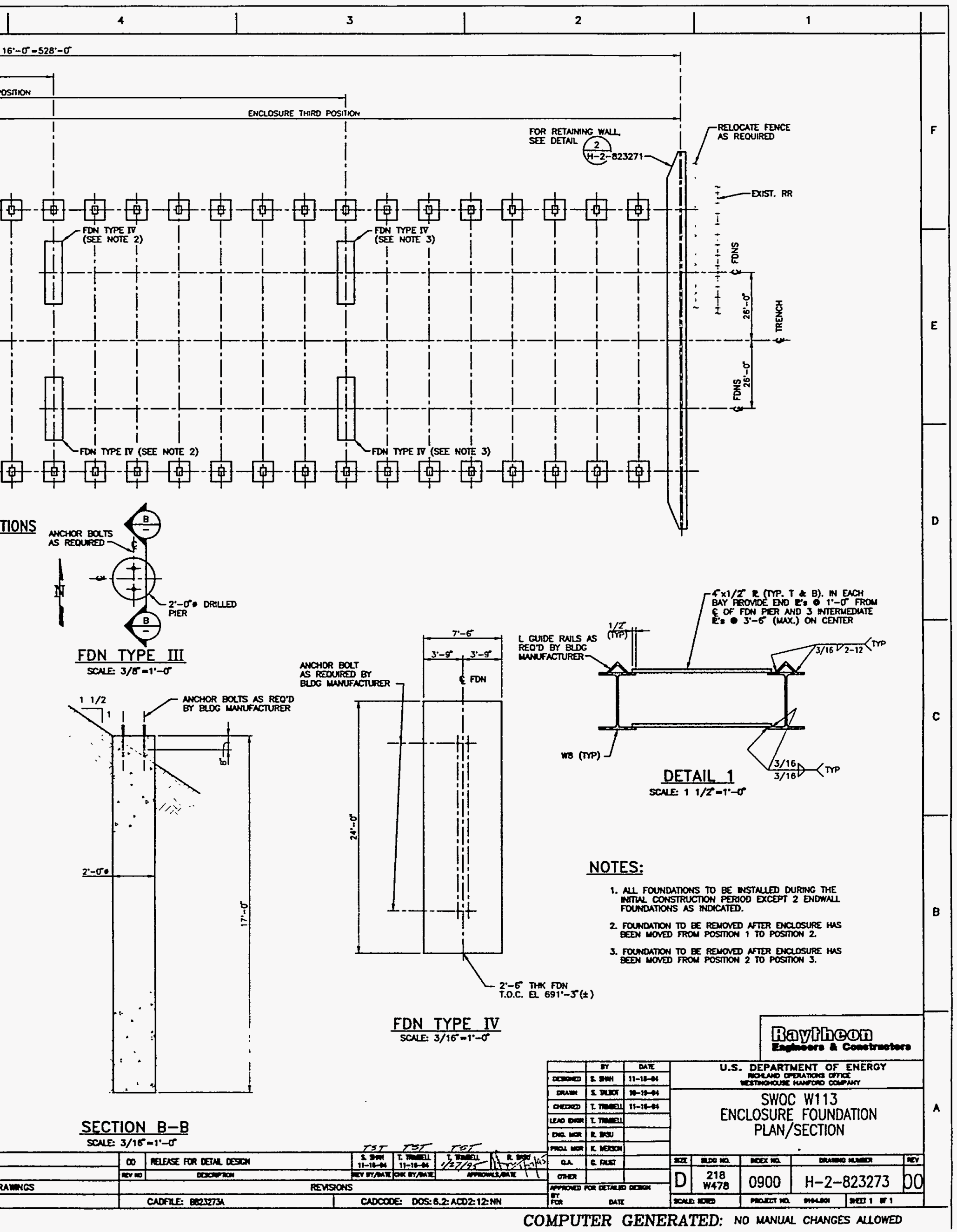




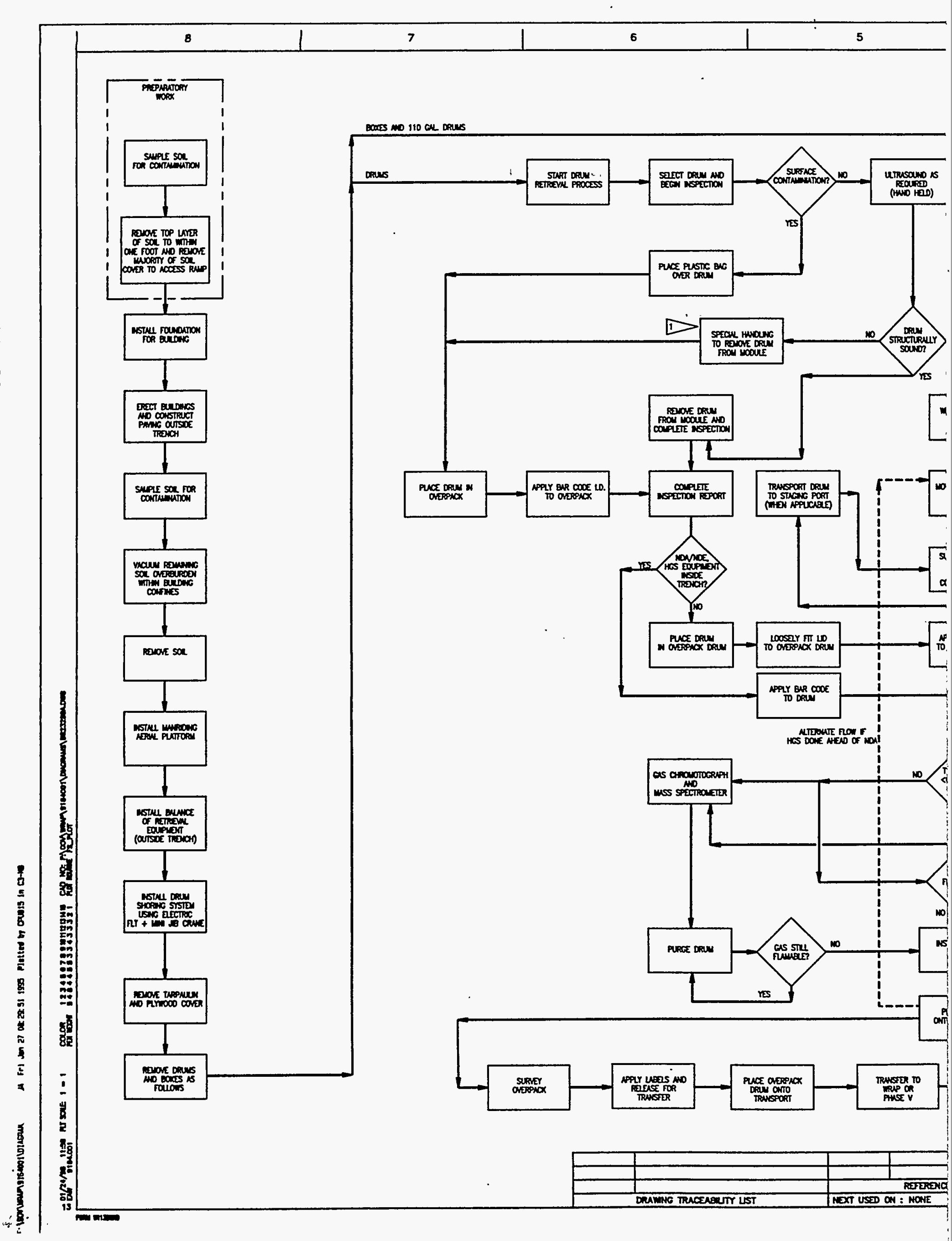




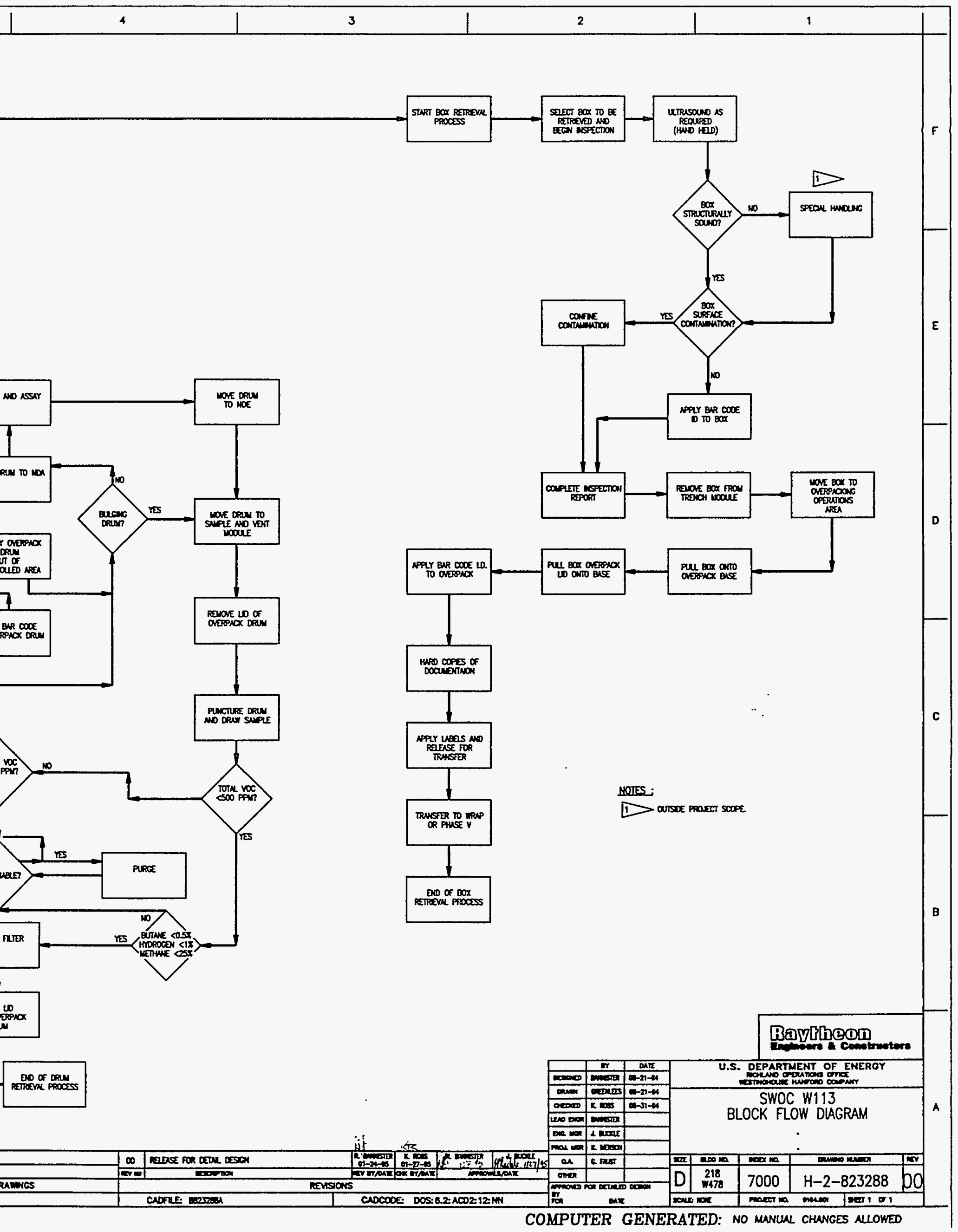




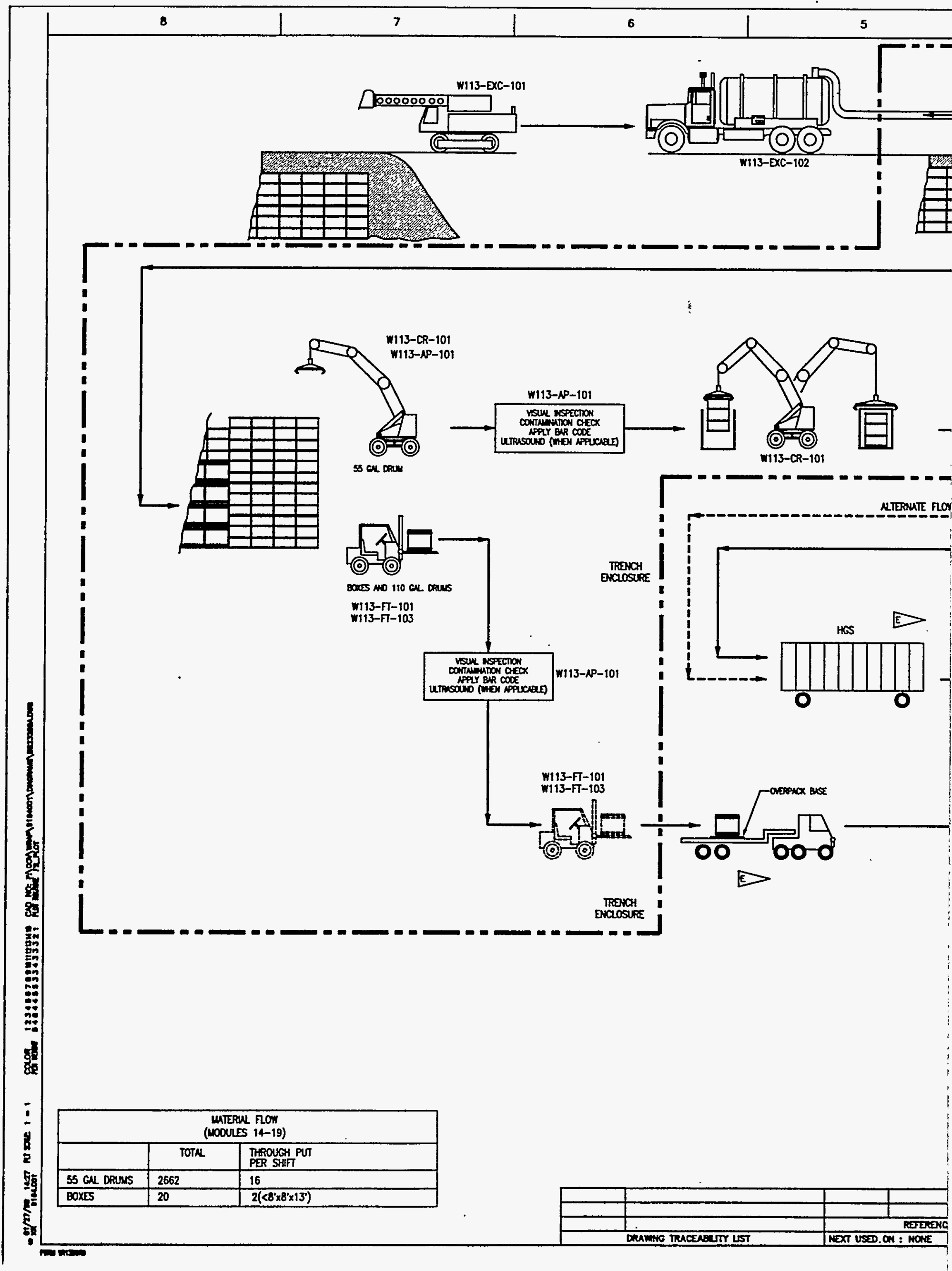




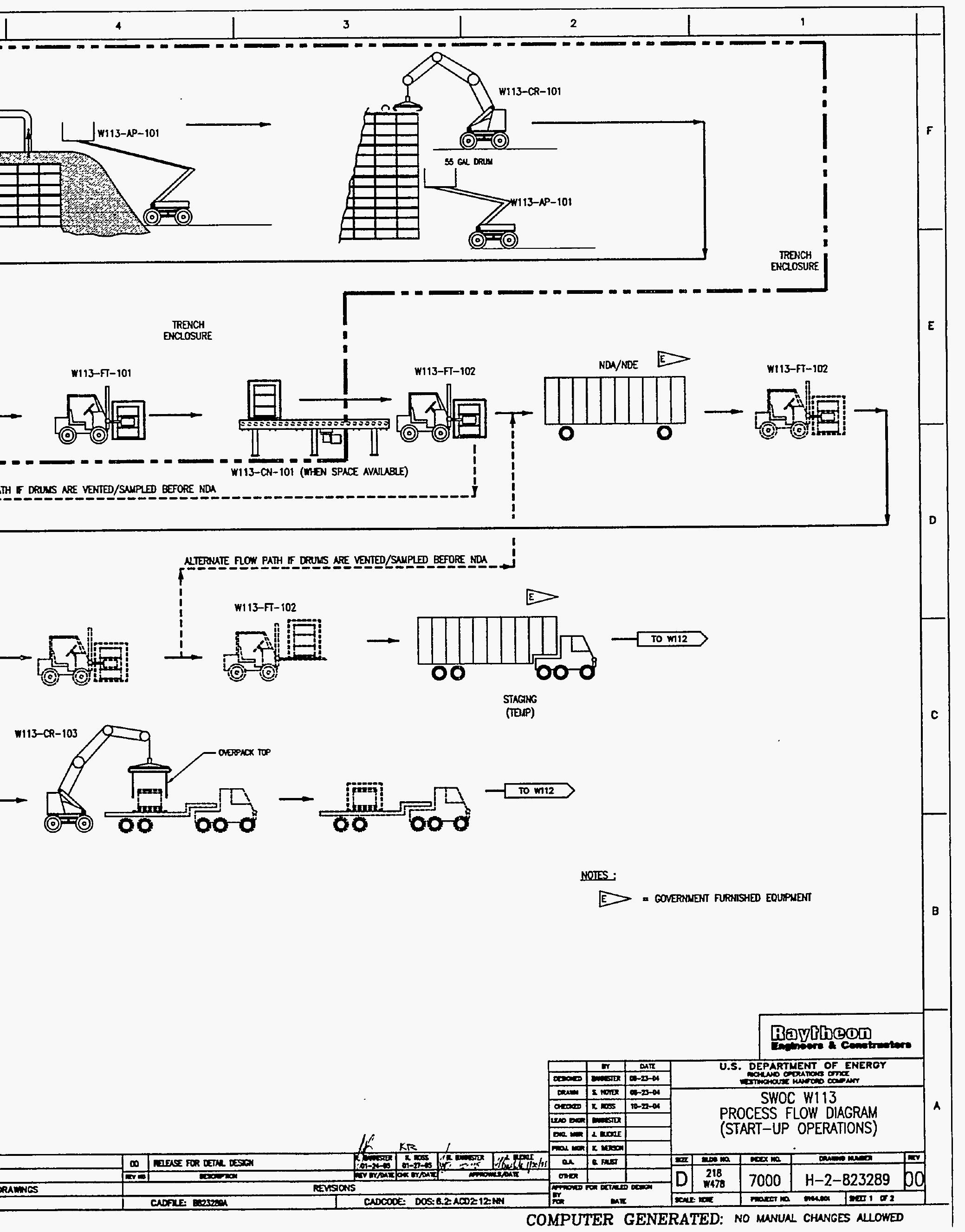




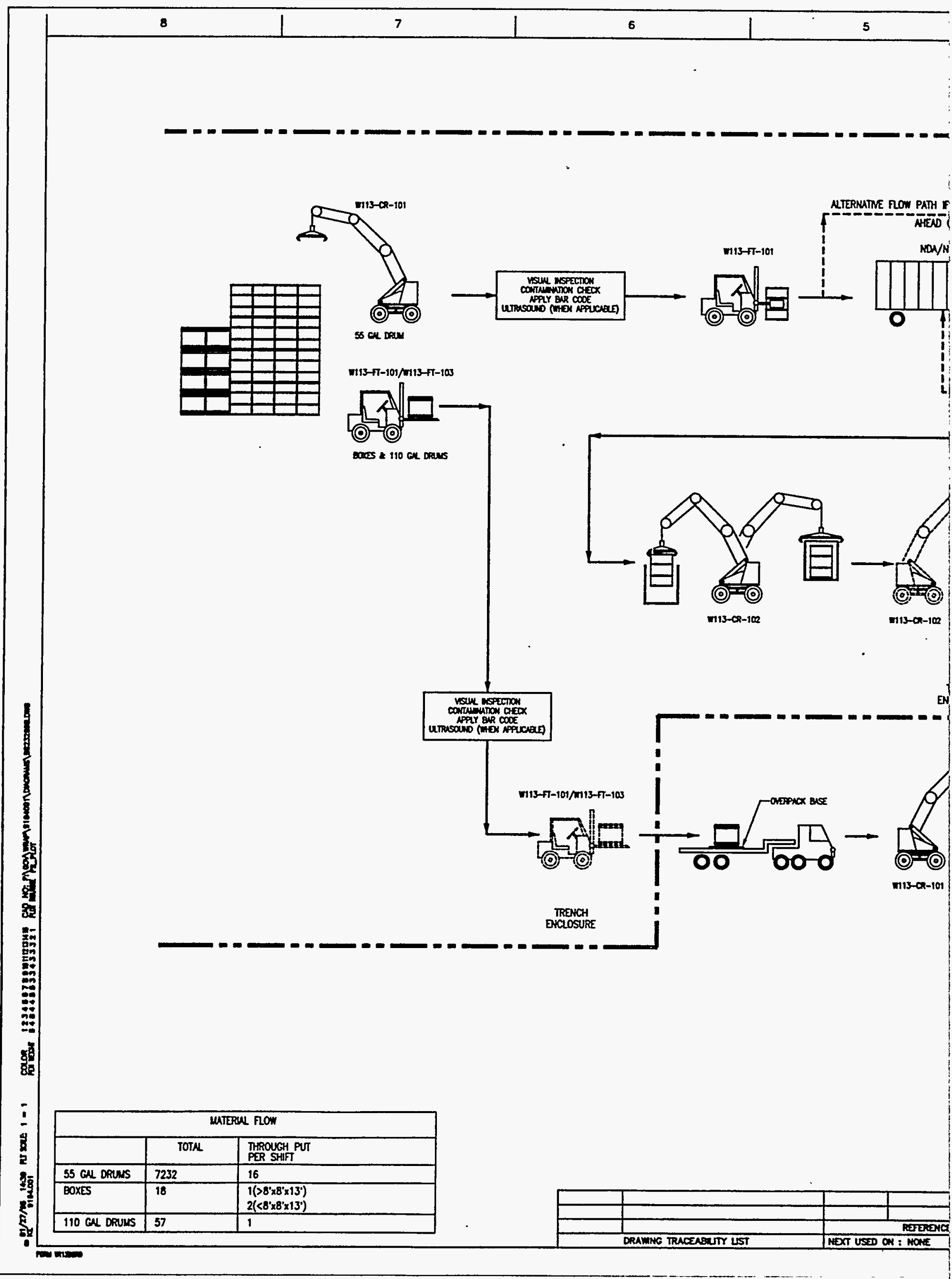




\begin{tabular}{|l|l|l|l|l|}
\hline 4 & 3 & 2 & 1 & 1 \\
\hline
\end{tabular}
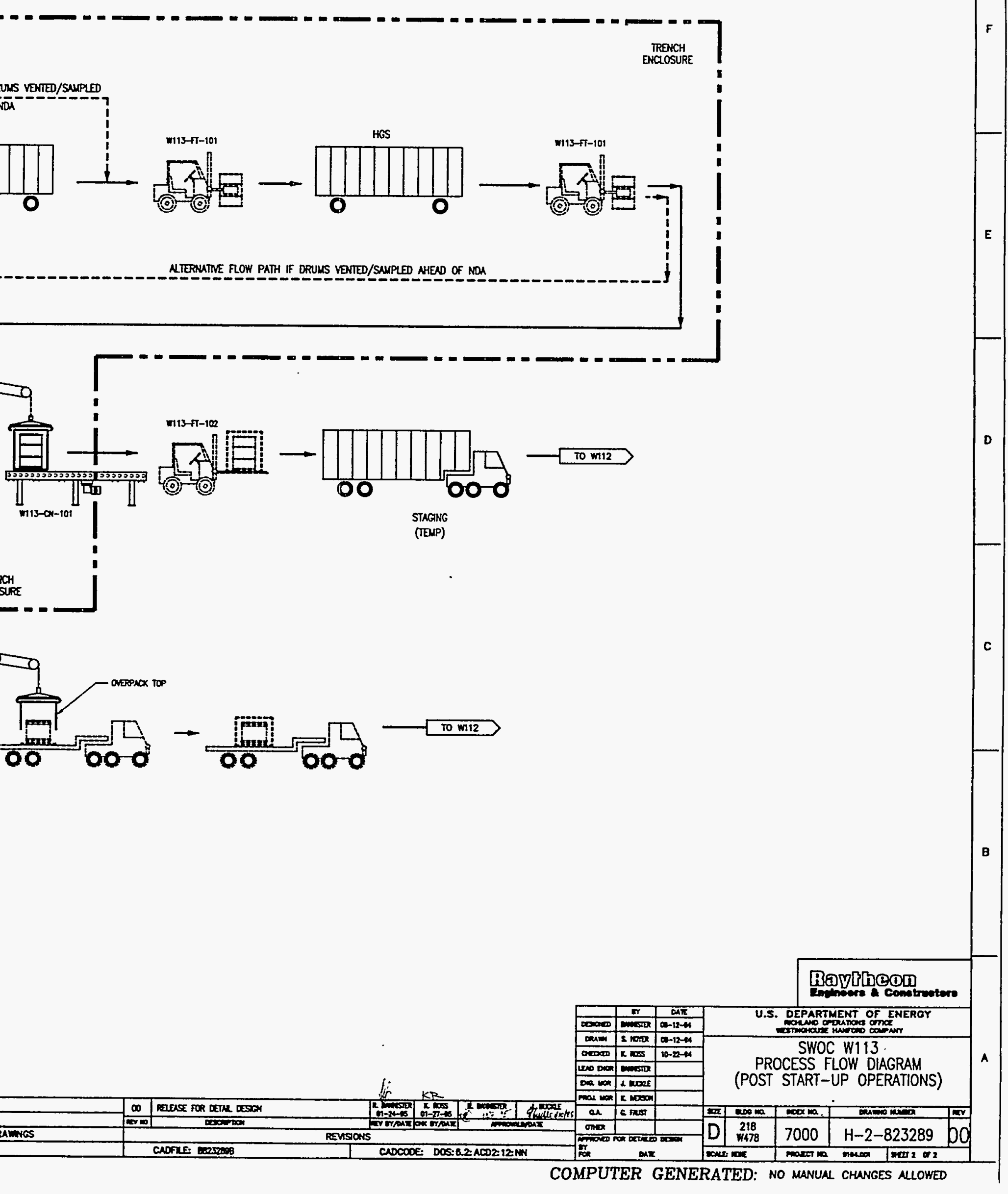


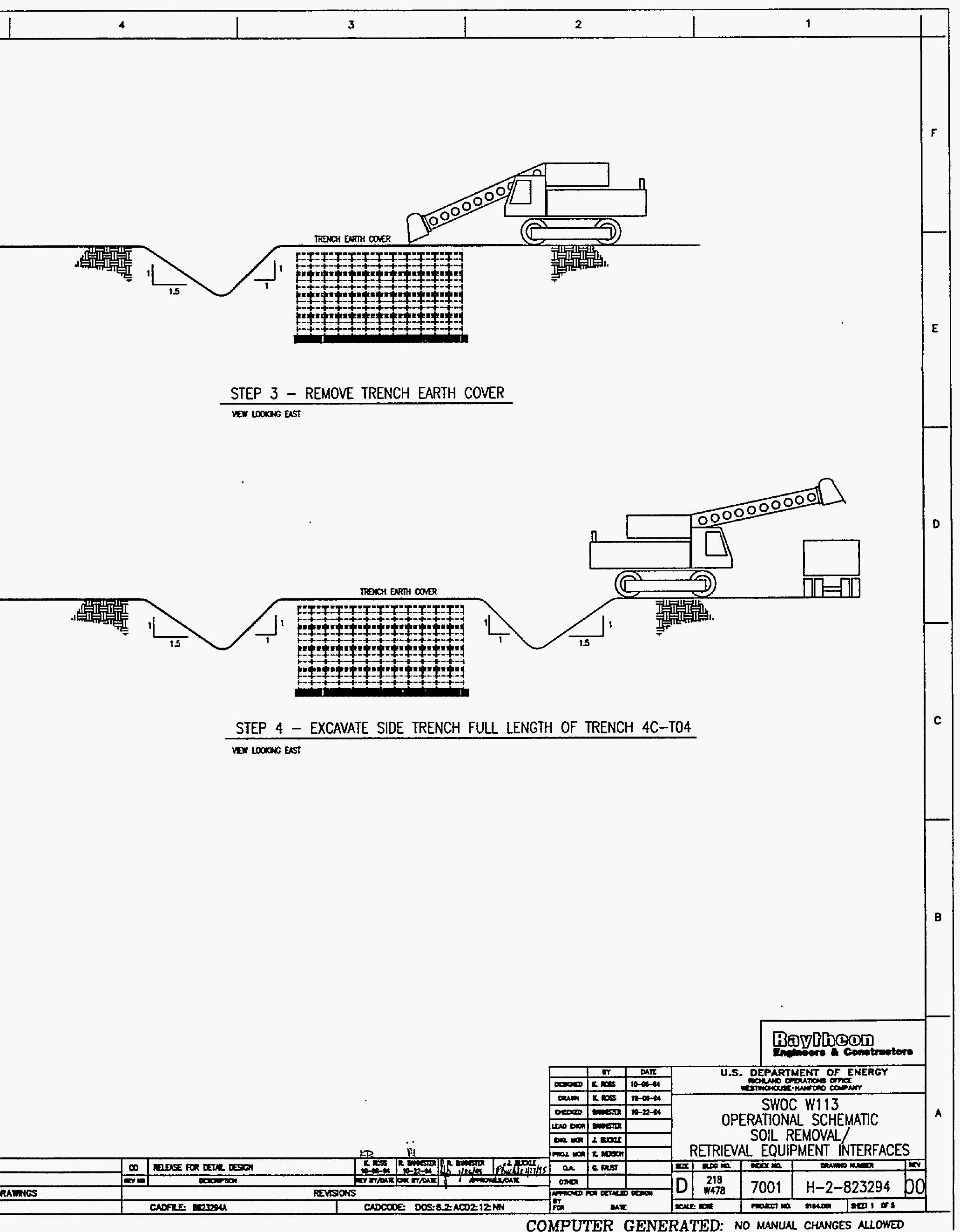




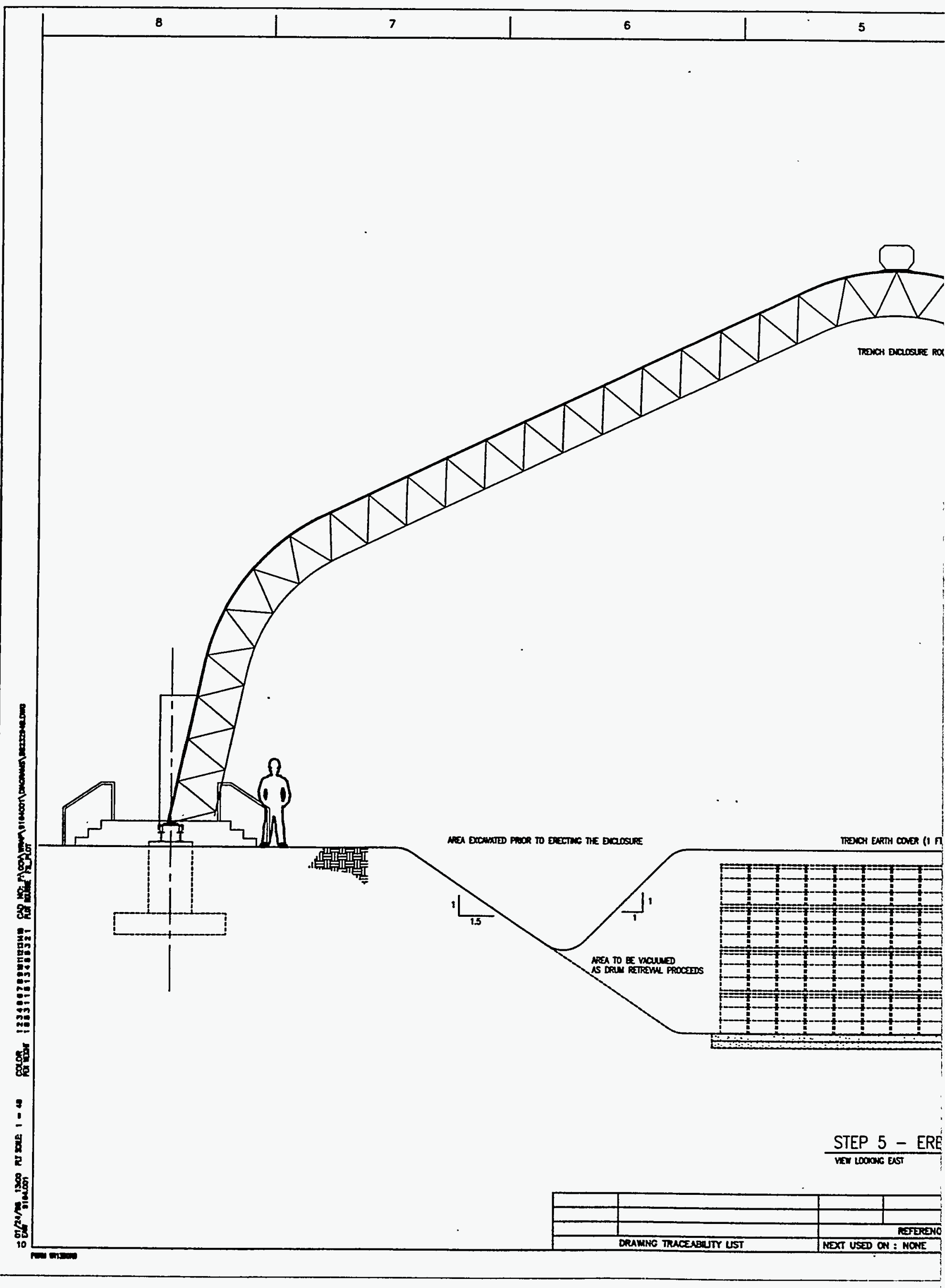




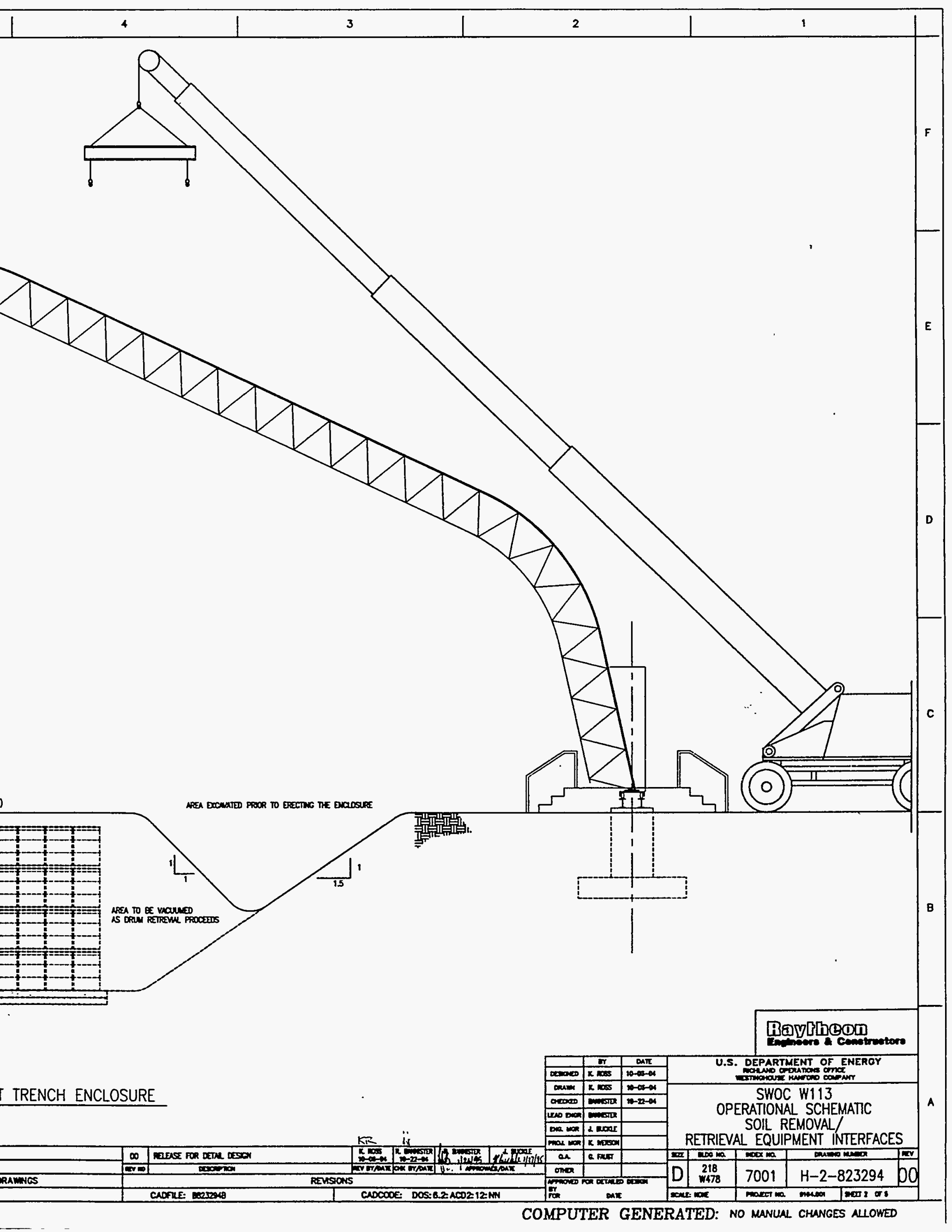




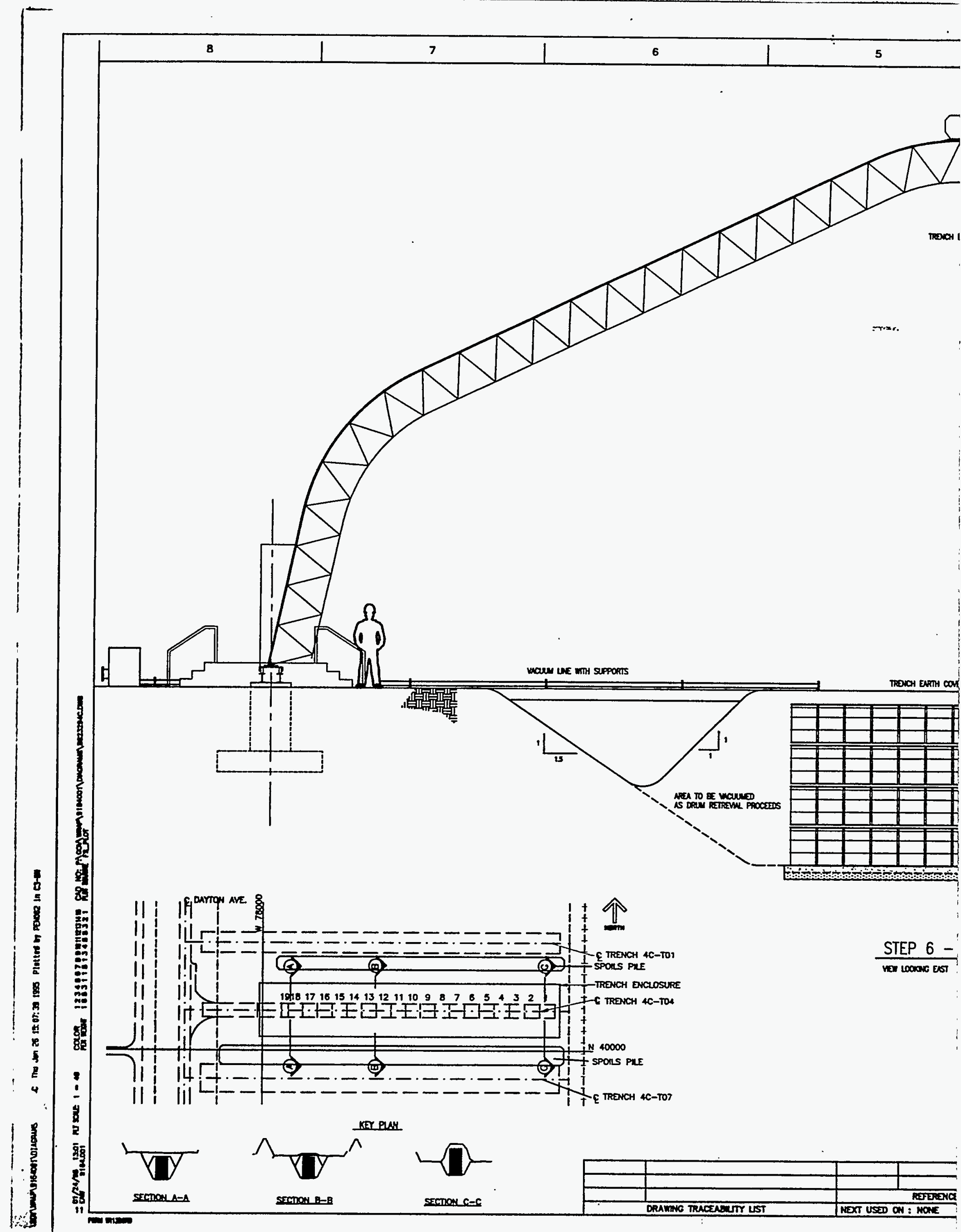




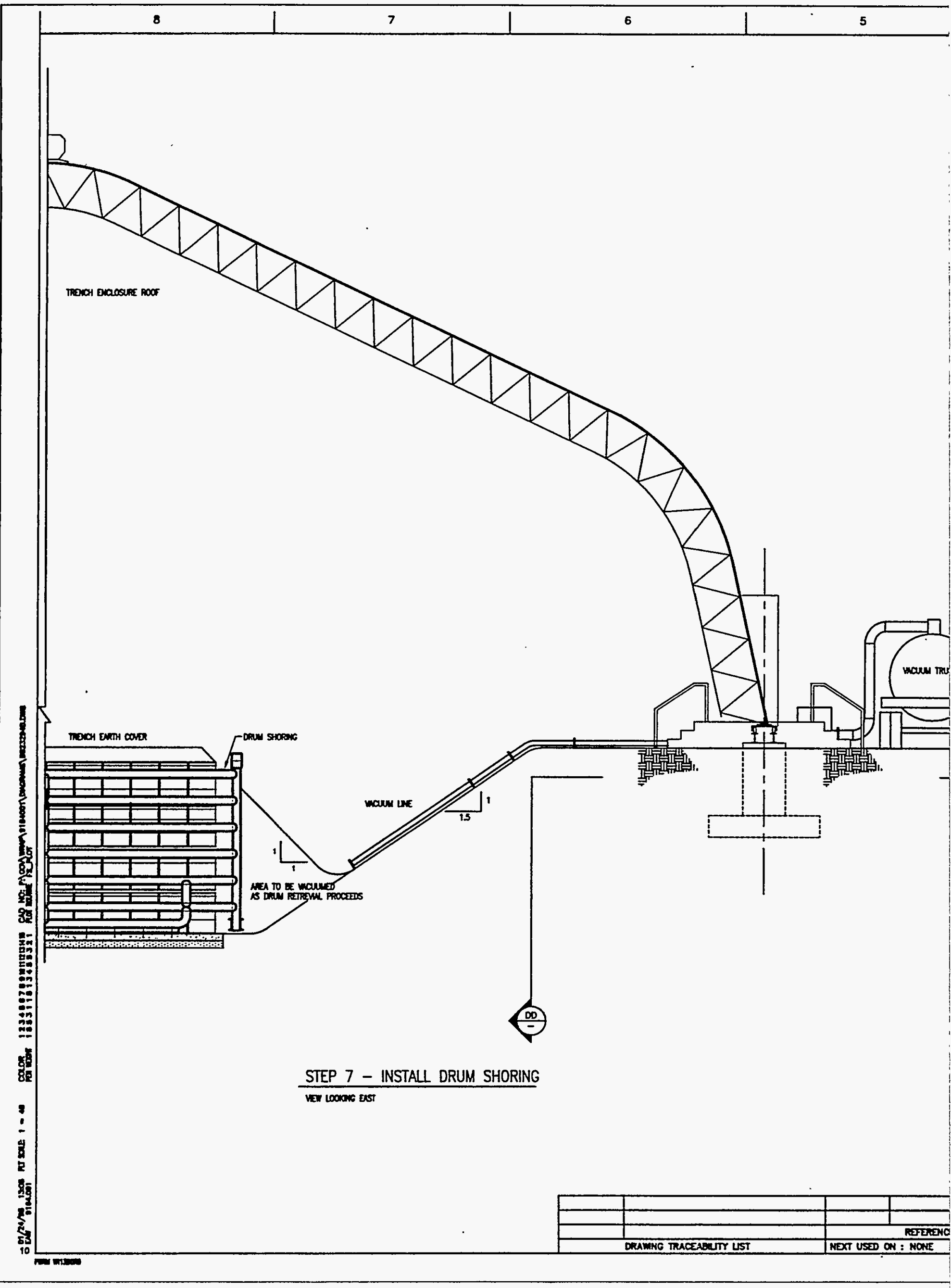




\begin{tabular}{|l|l|l|l|l|}
\hline 4 & 3 & 2 & 1 & 1 \\
\hline
\end{tabular}
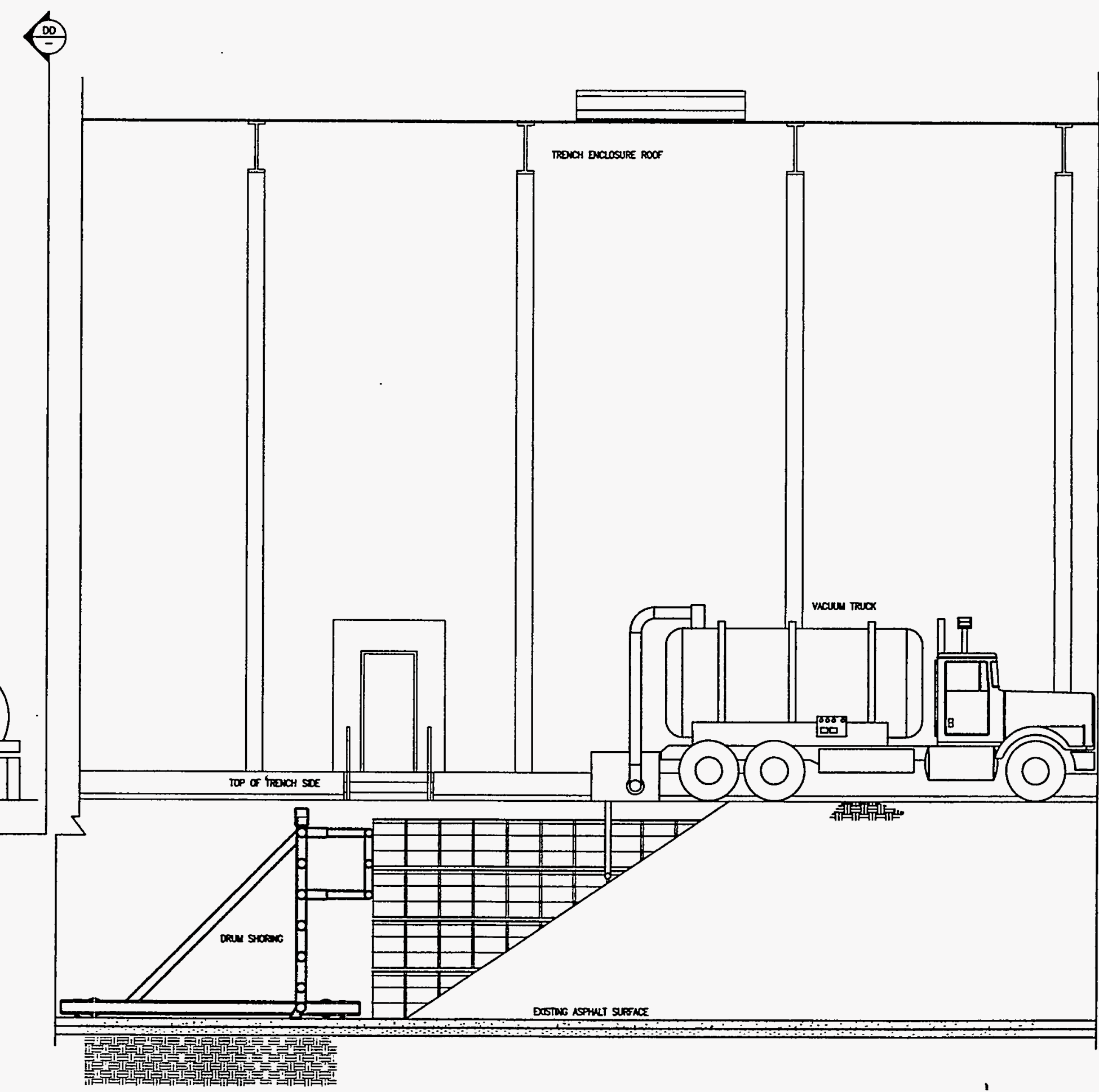

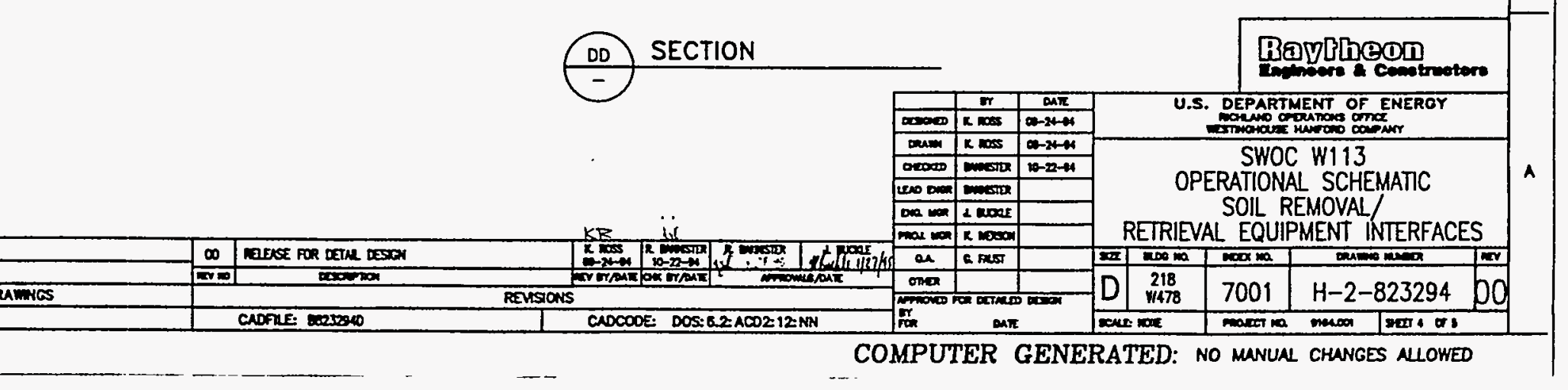




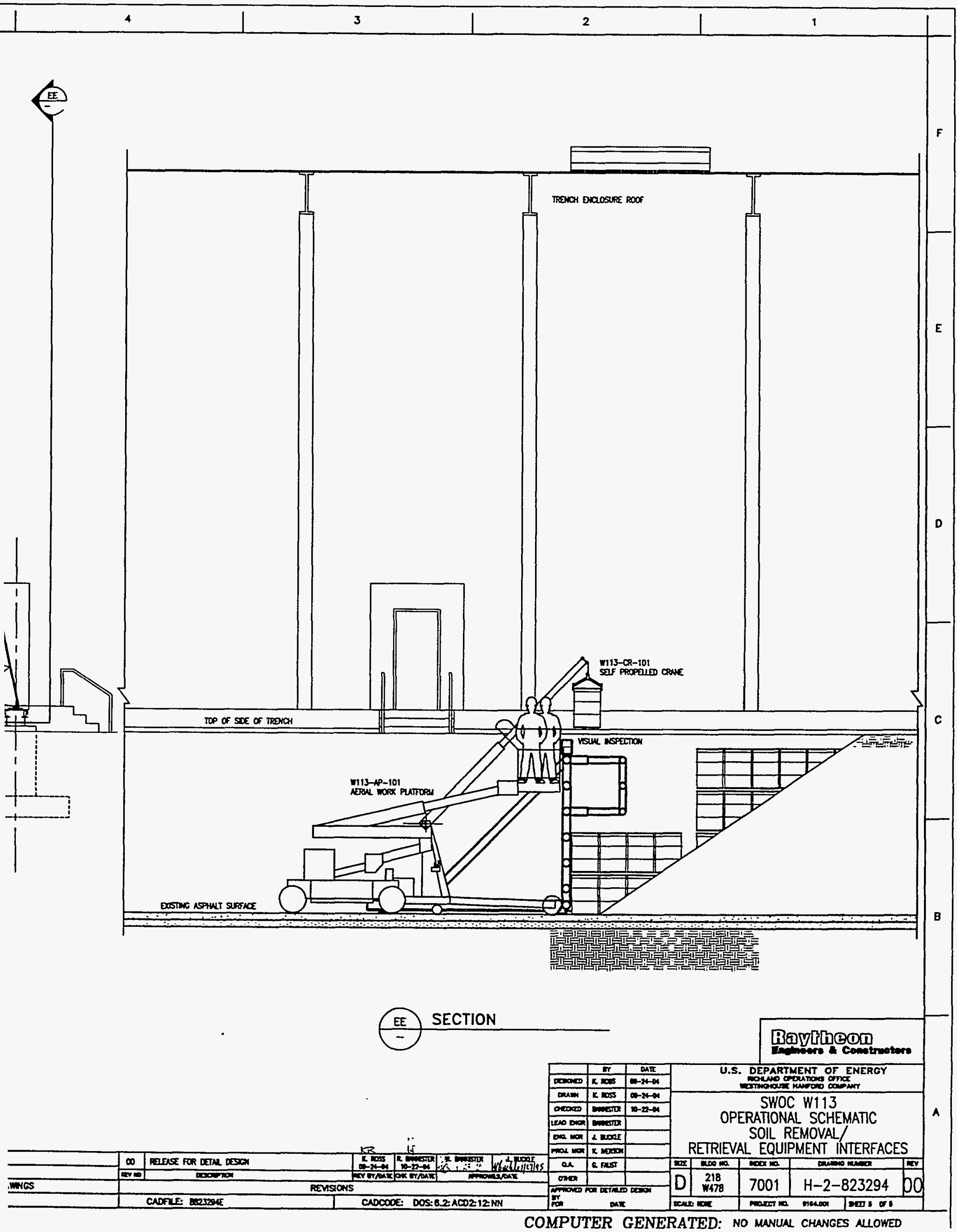




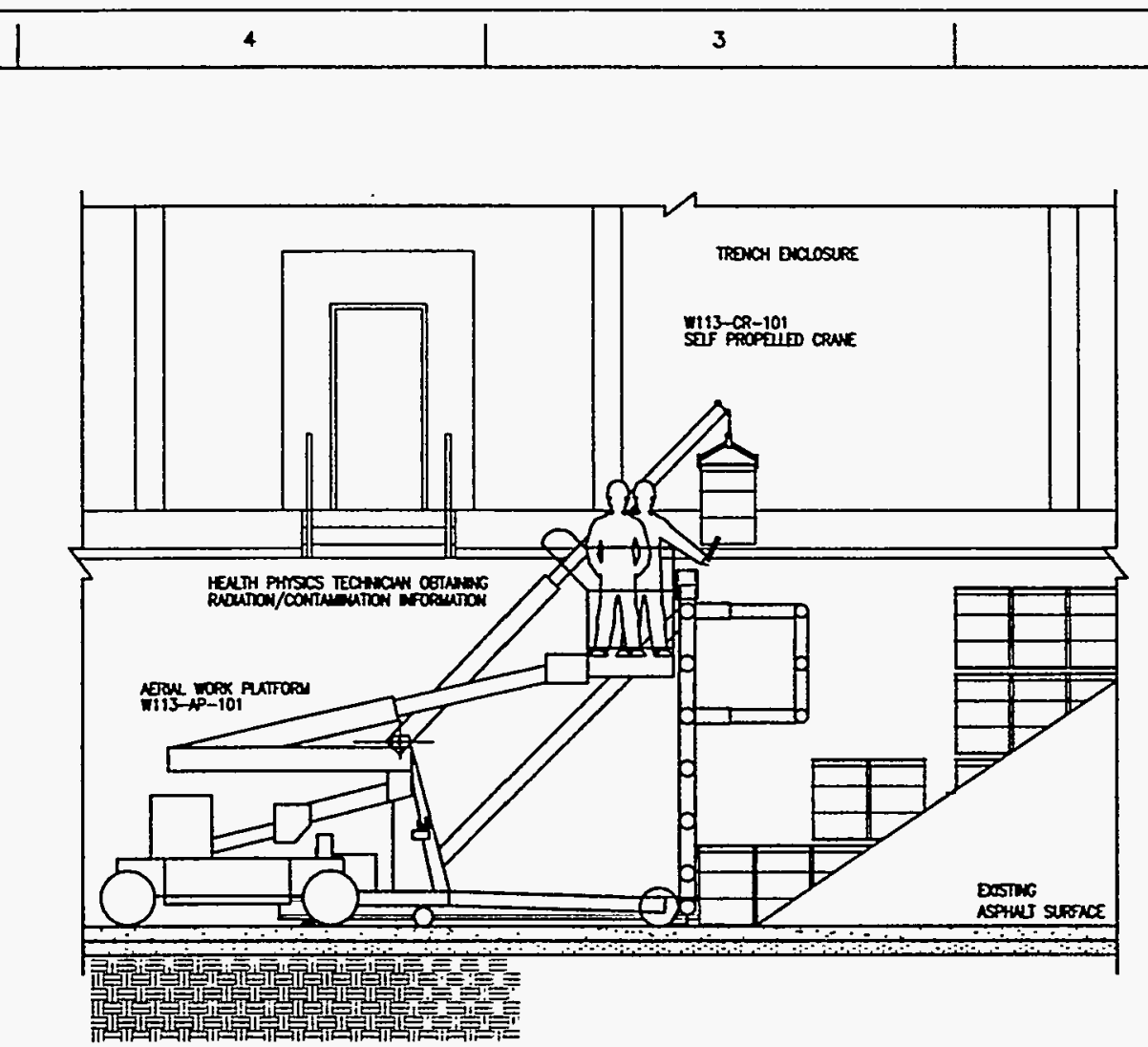

2

FF SECTION (REMOVAL OF LEVEL 2 DRUMS)
H-2-823295 SHT 2

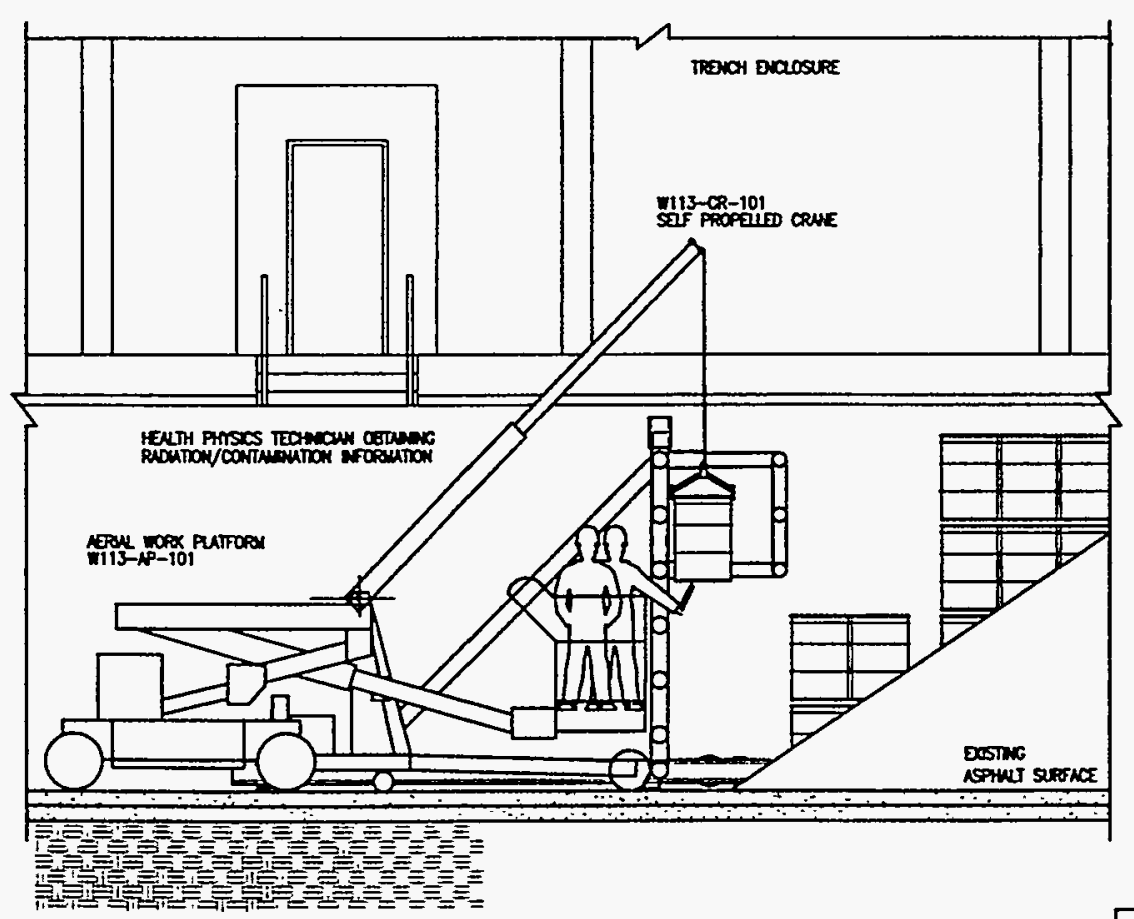

D

c

FF SECTION (REMOVAL OF LEVEL 1 DRUMS) H-2-823295 SHT 2

\begin{tabular}{|c|c|c|}
\hline & $\pi$ & antr \\
\hline nowion & $x \cos$ & $0-2 x-2$ \\
\hline mentin & $\alpha \operatorname{coss}$ & $0-24-$ \\
\hline 0000 & omesias & $20-20$ \\
\hline tees and & $a_{0}$ & \\
\hline Dom & 12000 & \\
\hline mosen & K mason & \\
\hline al & 6 moss & \\
\hline oner & & \\
\hline
\end{tabular}

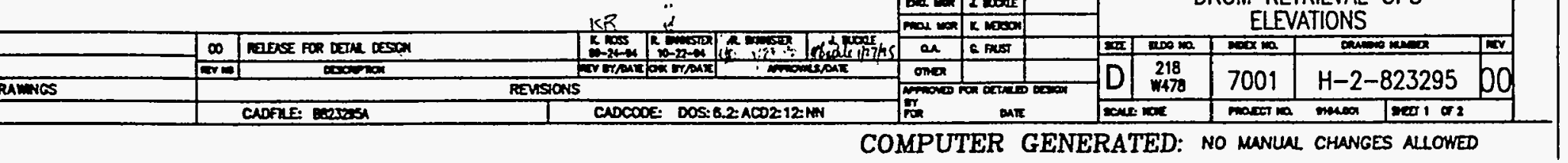




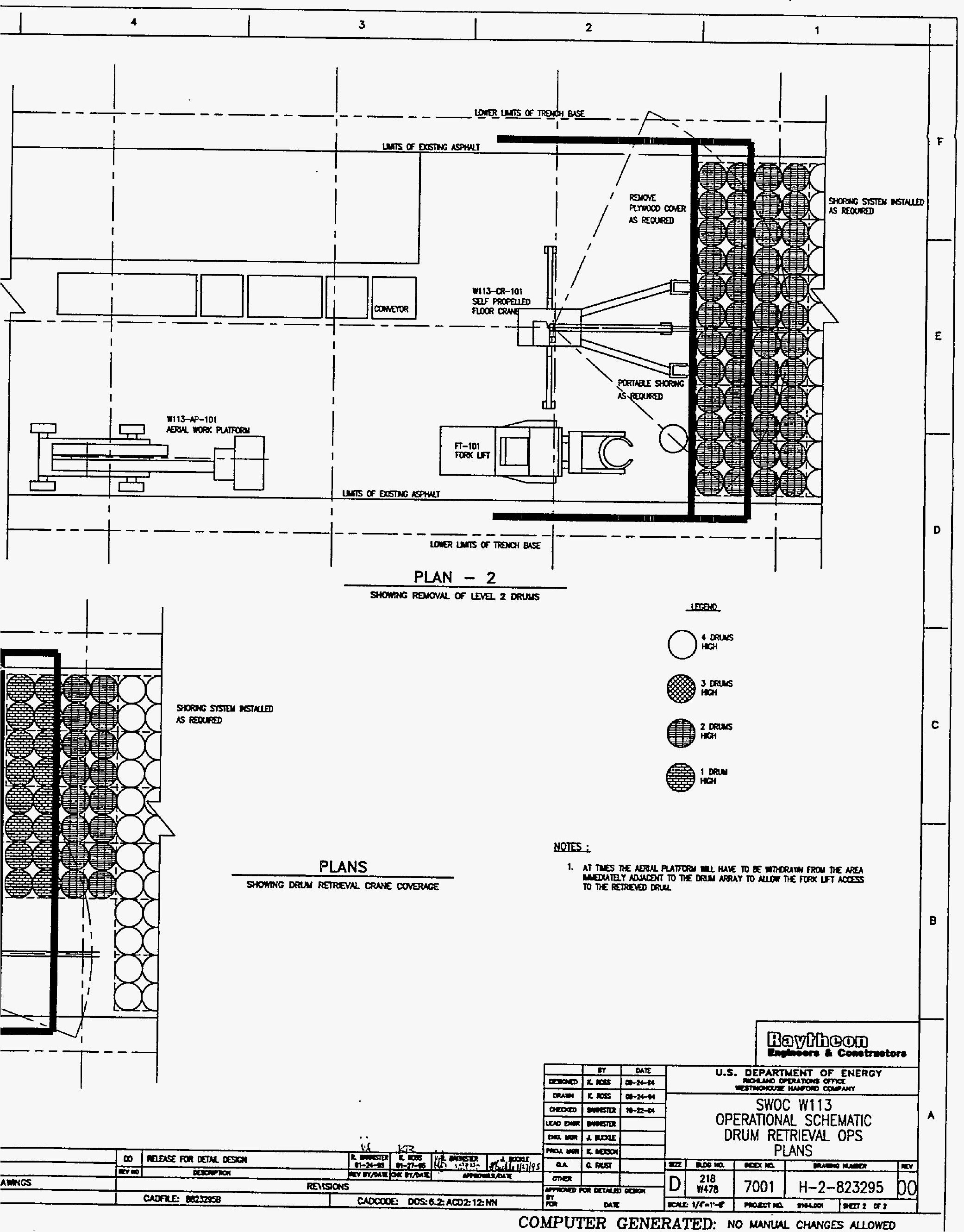




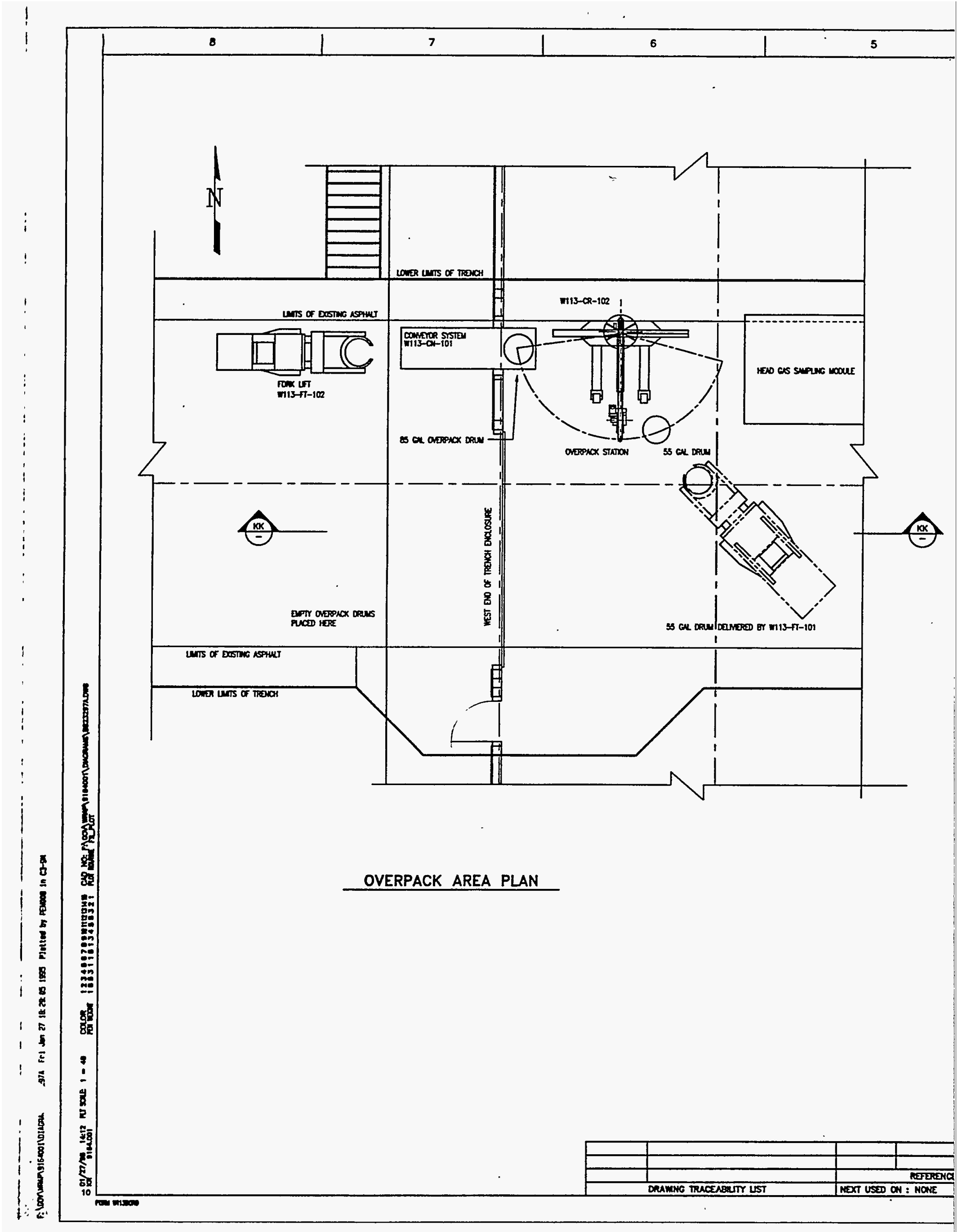




\begin{tabular}{|l|l|l|l|l|}
\hline 4 & 3 & 2 & 1 & 1 \\
\hline
\end{tabular}

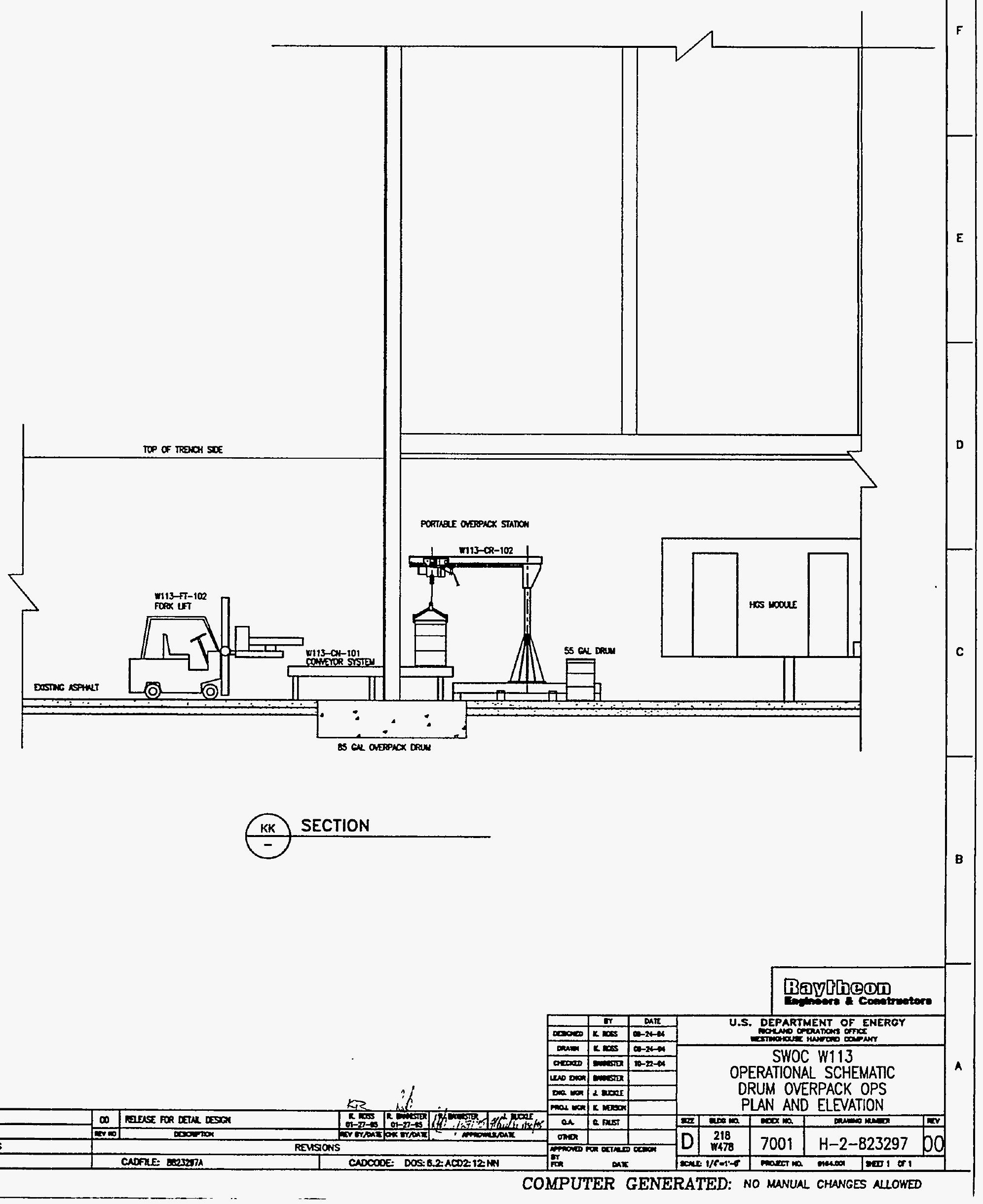




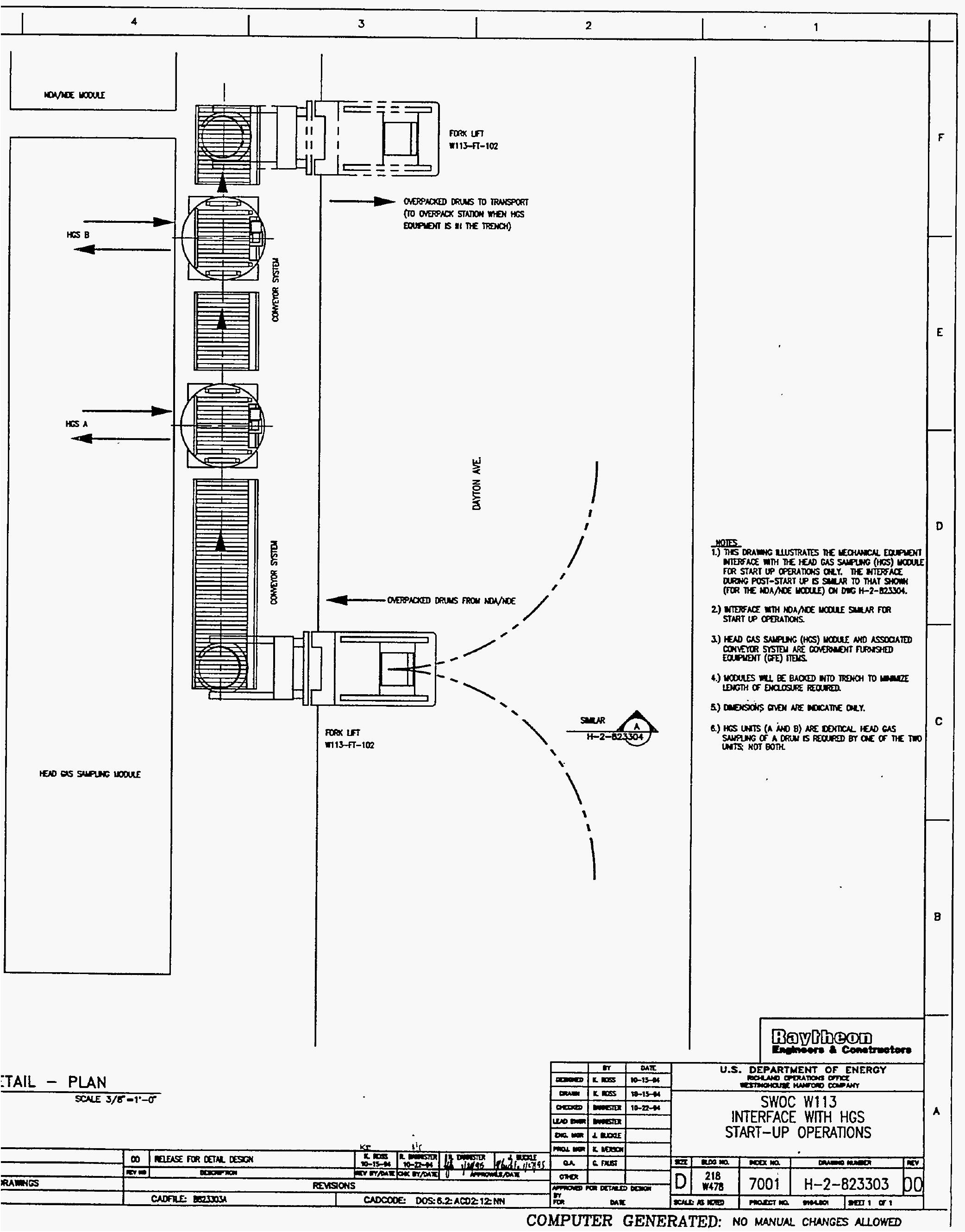




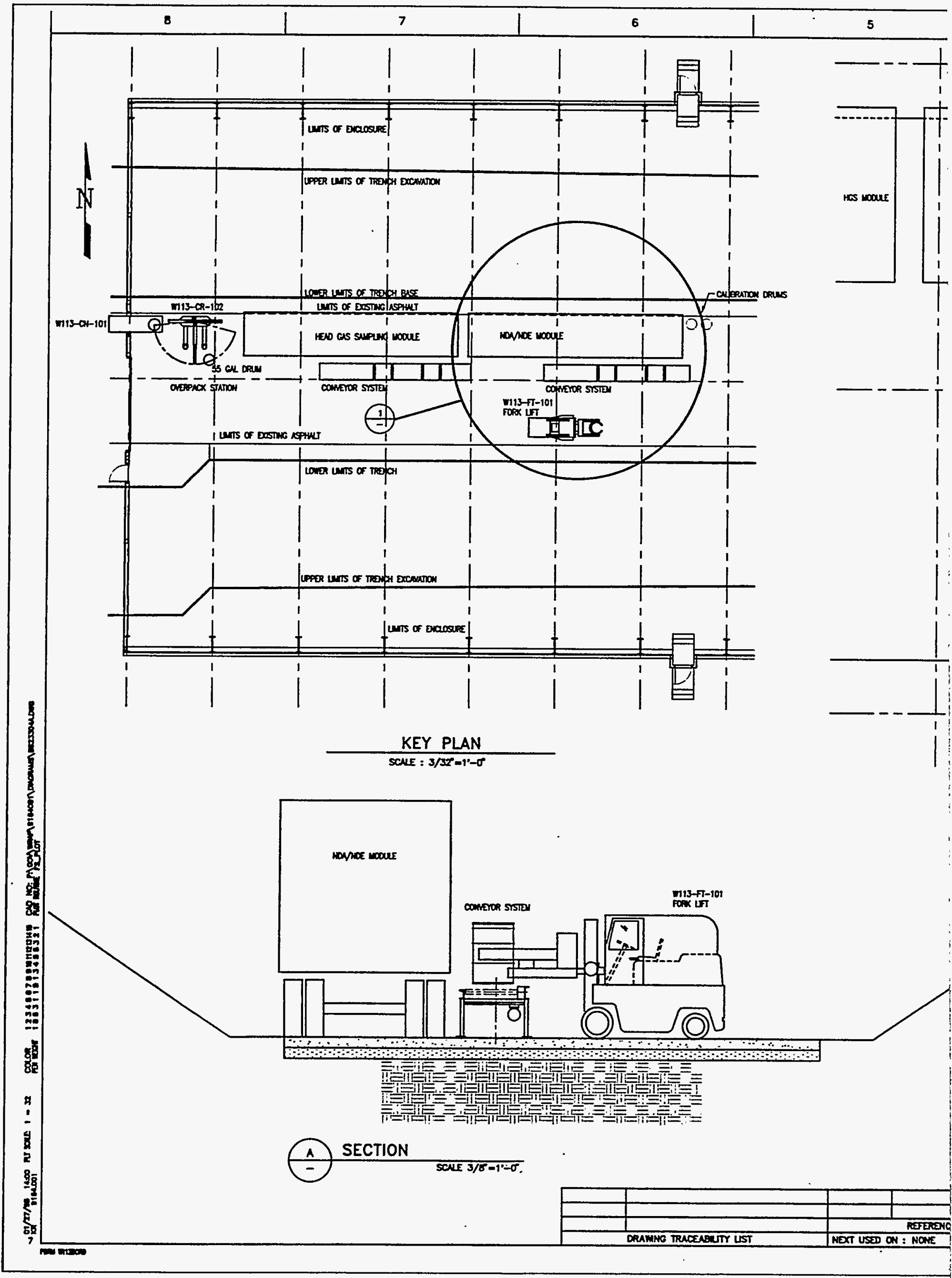




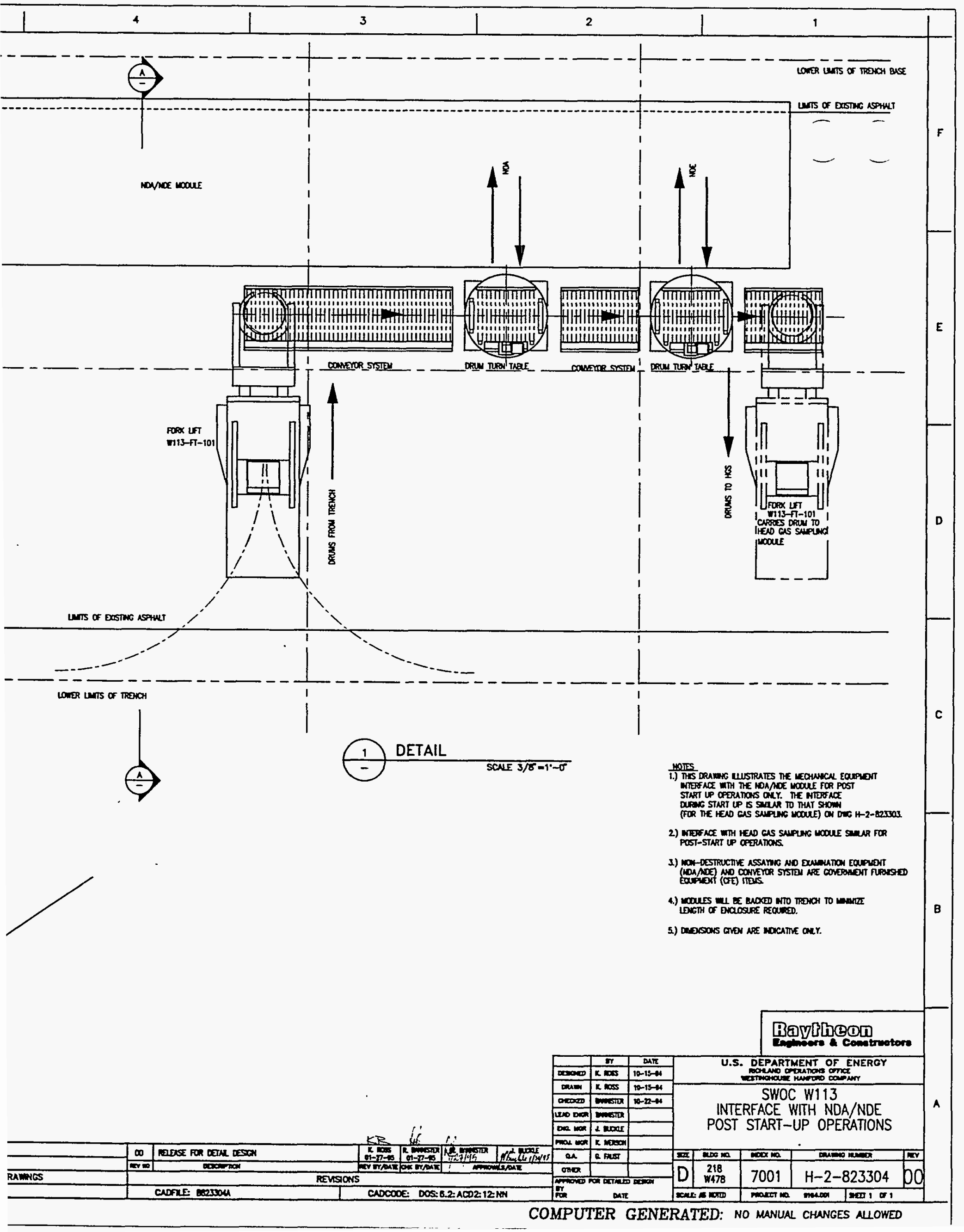




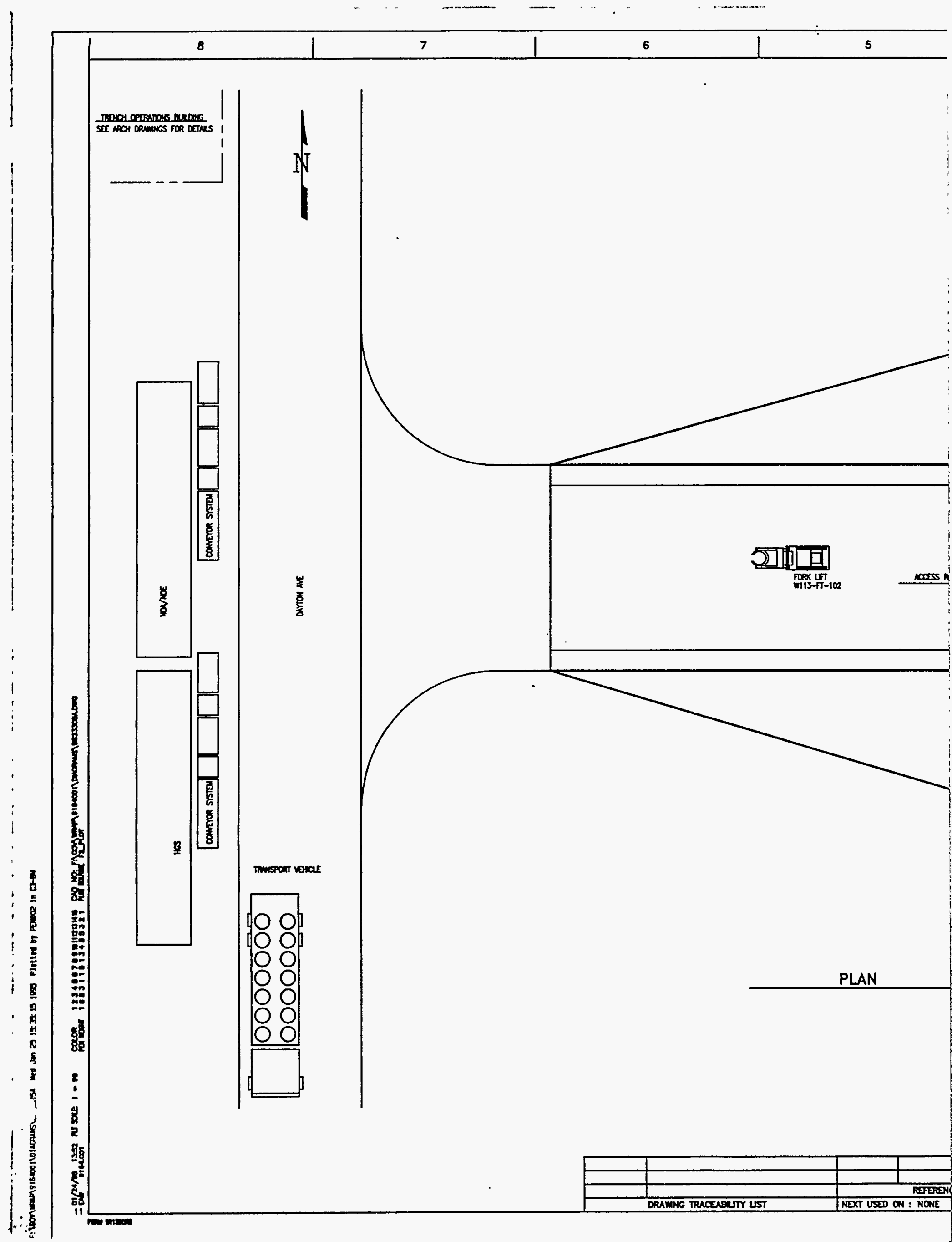




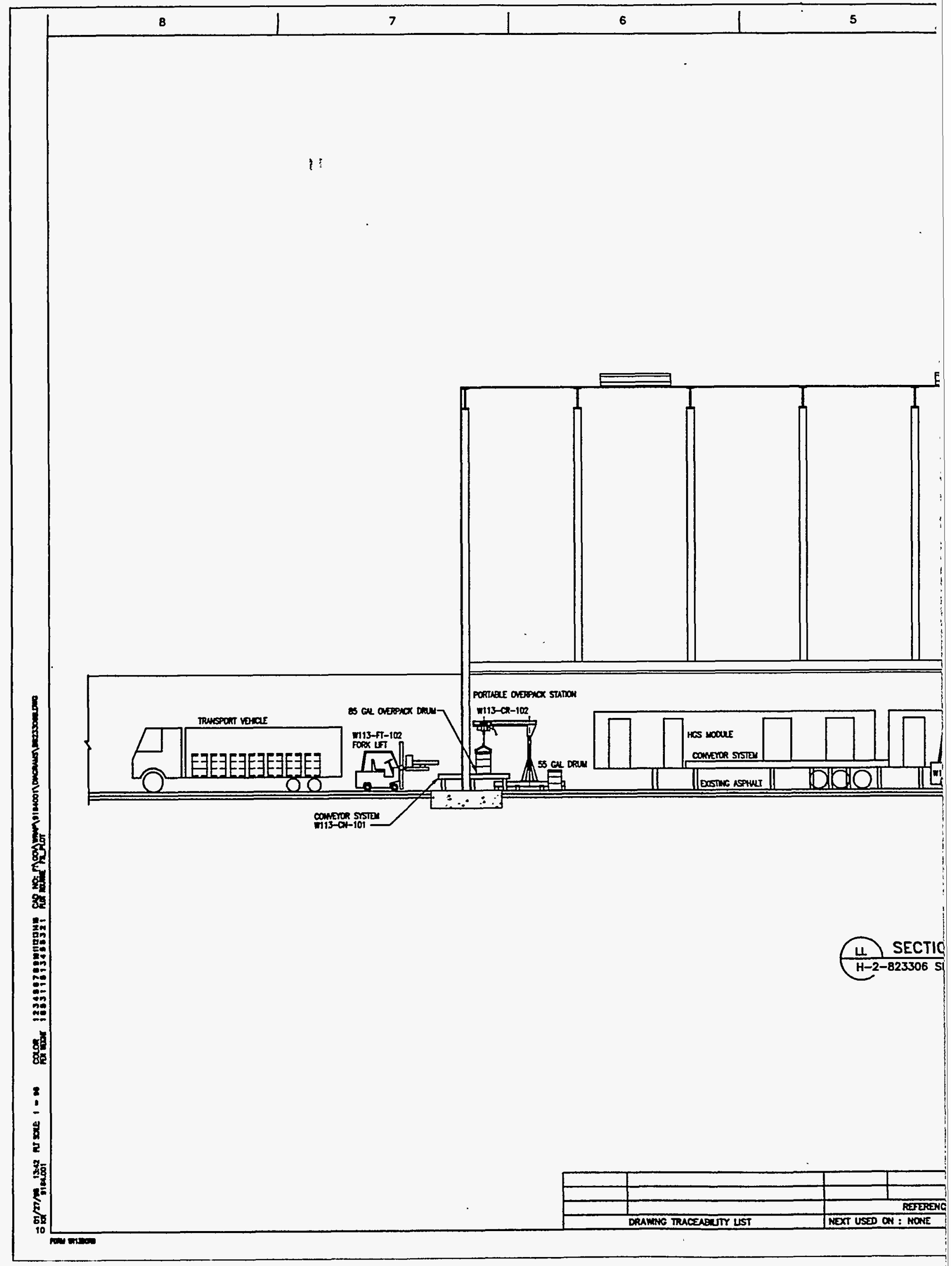




\begin{tabular}{|l|l|l|l|l|}
\hline & 4 & 3 & 2 & 1 \\
\hline
\end{tabular}

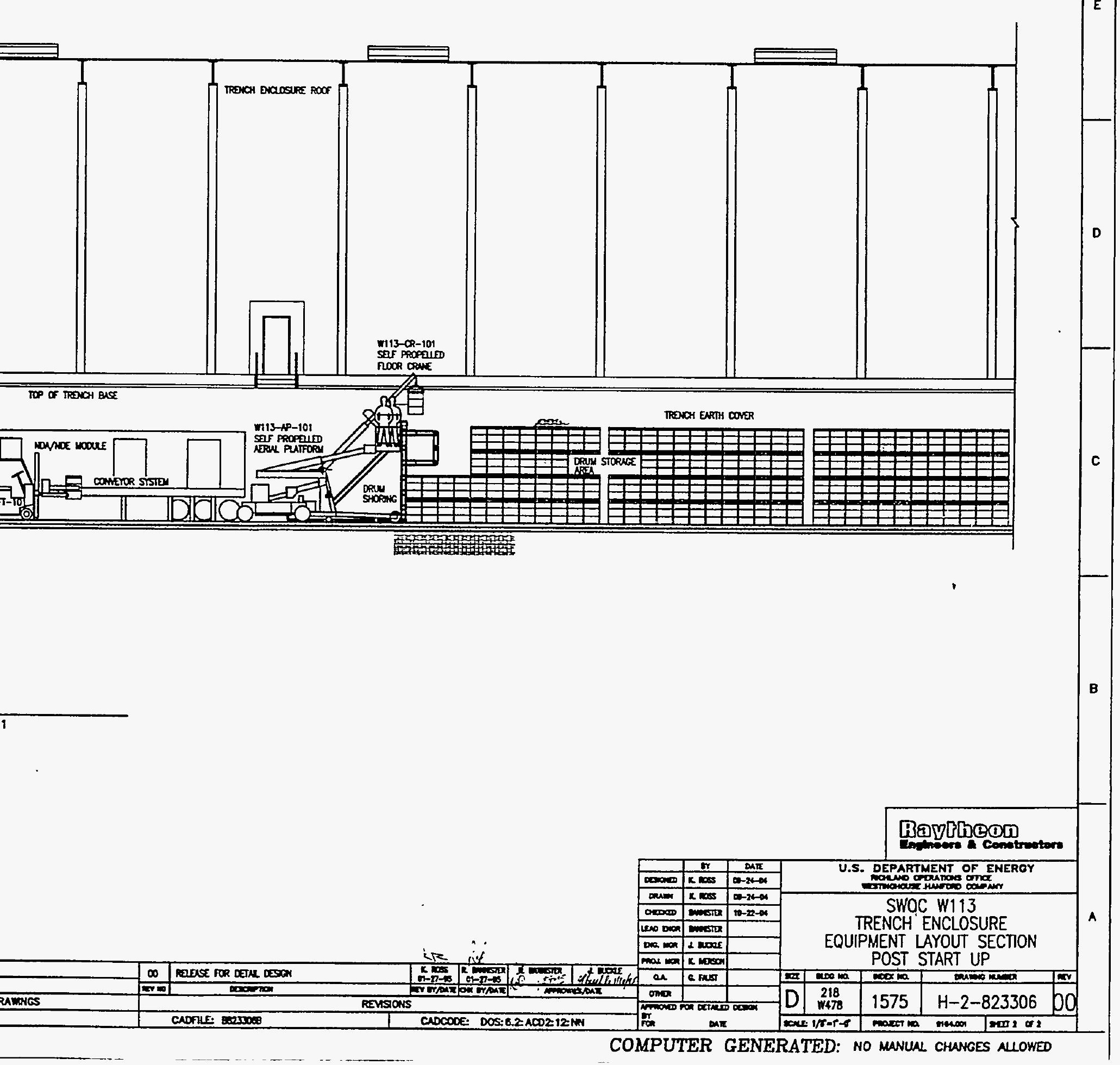




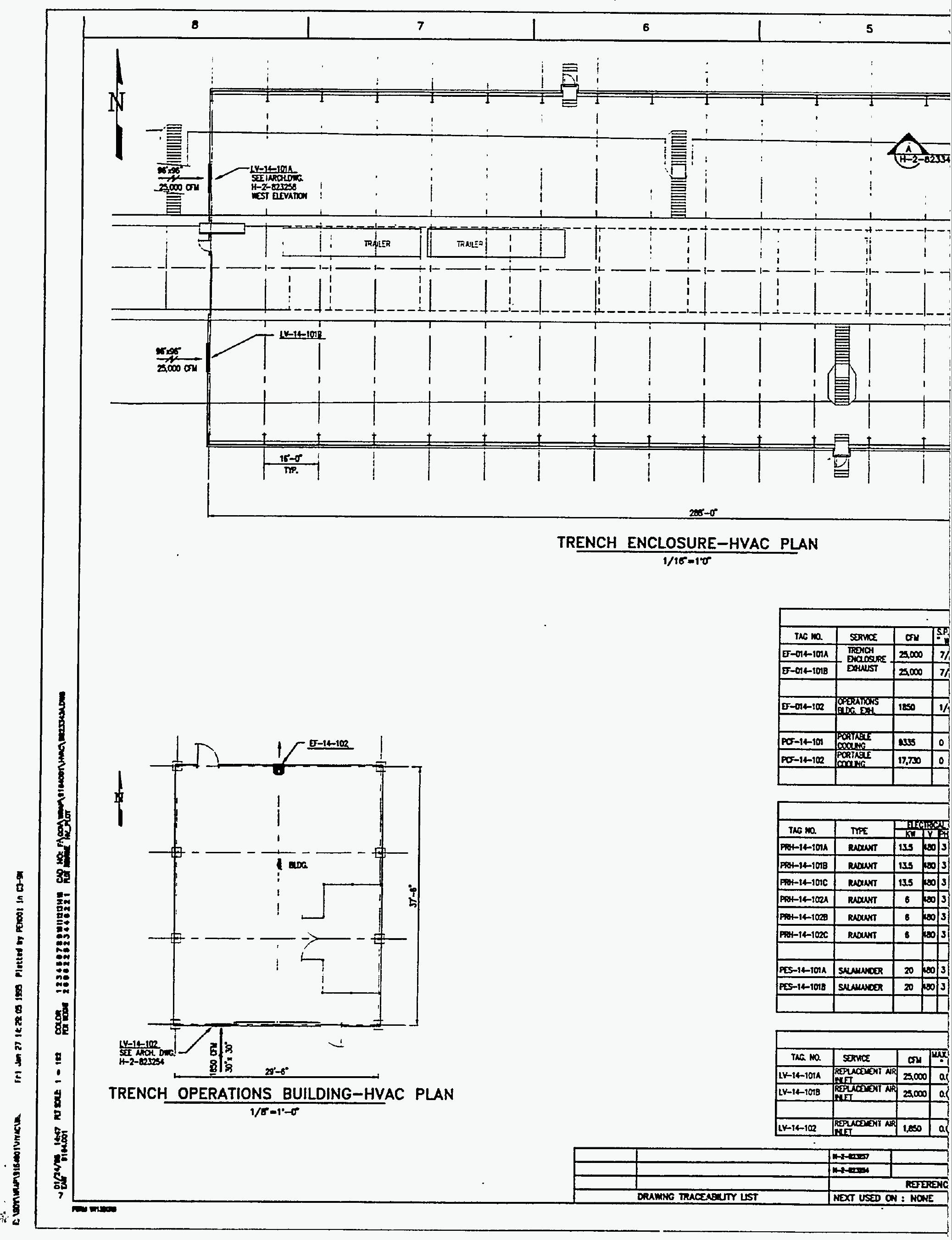




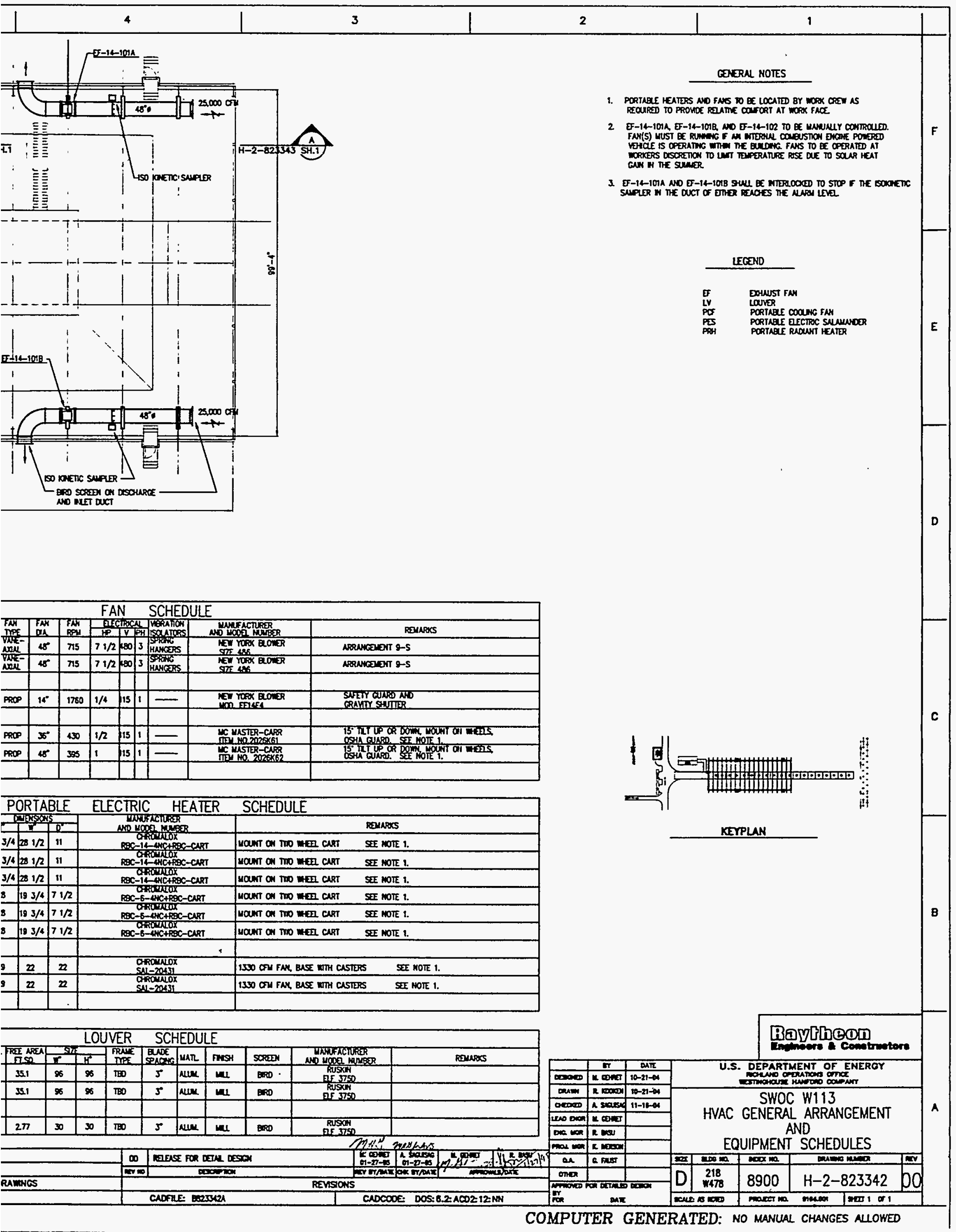




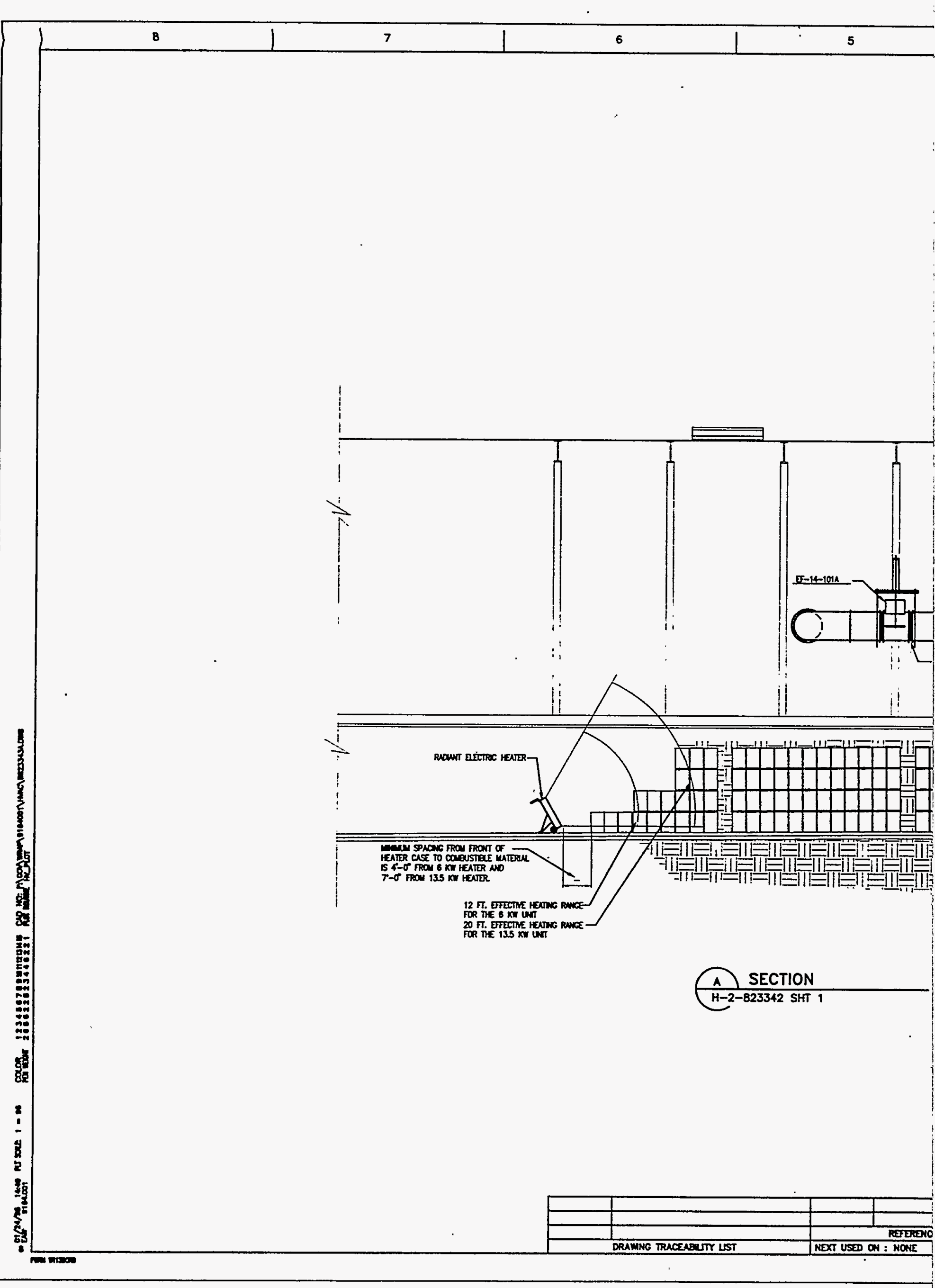




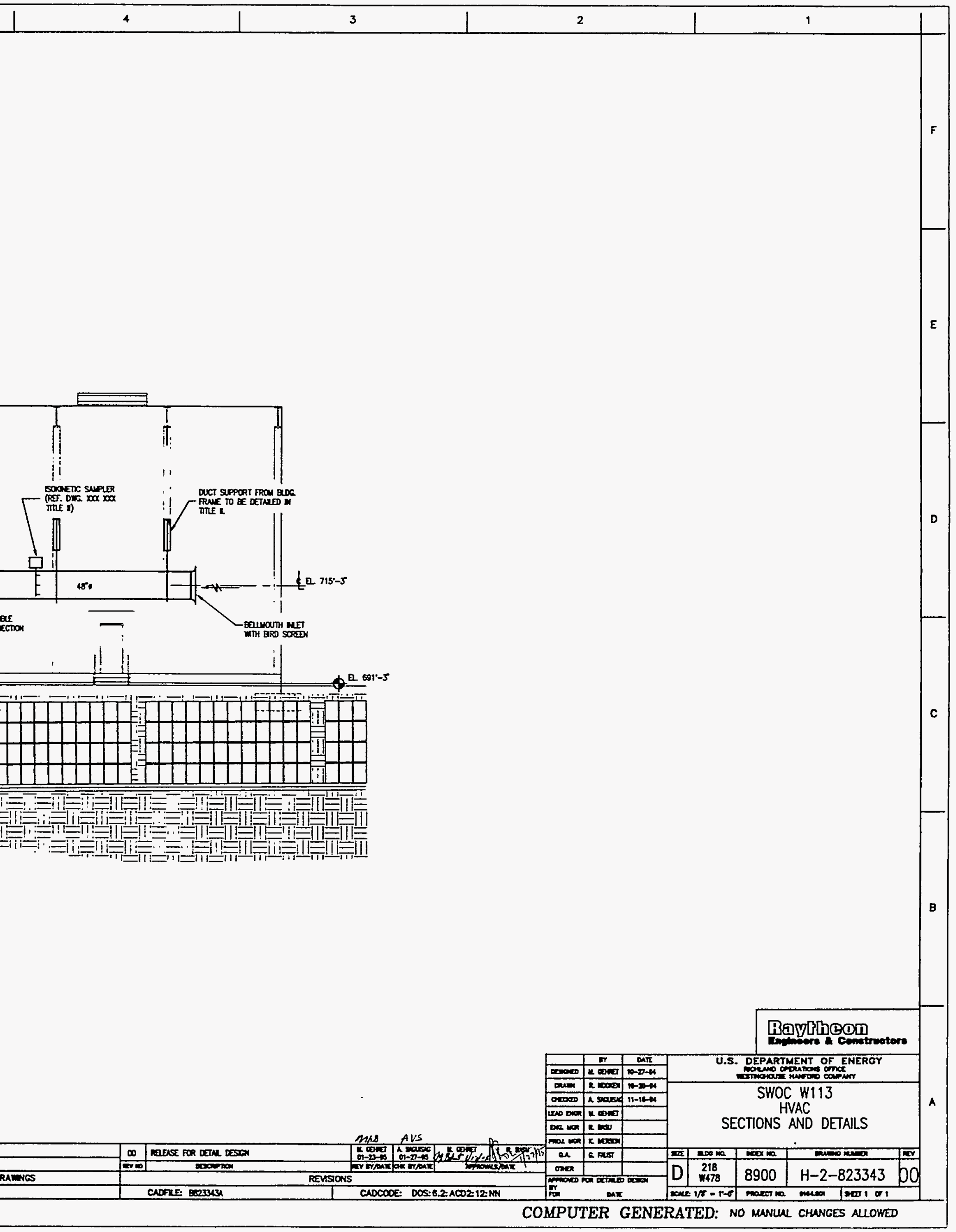




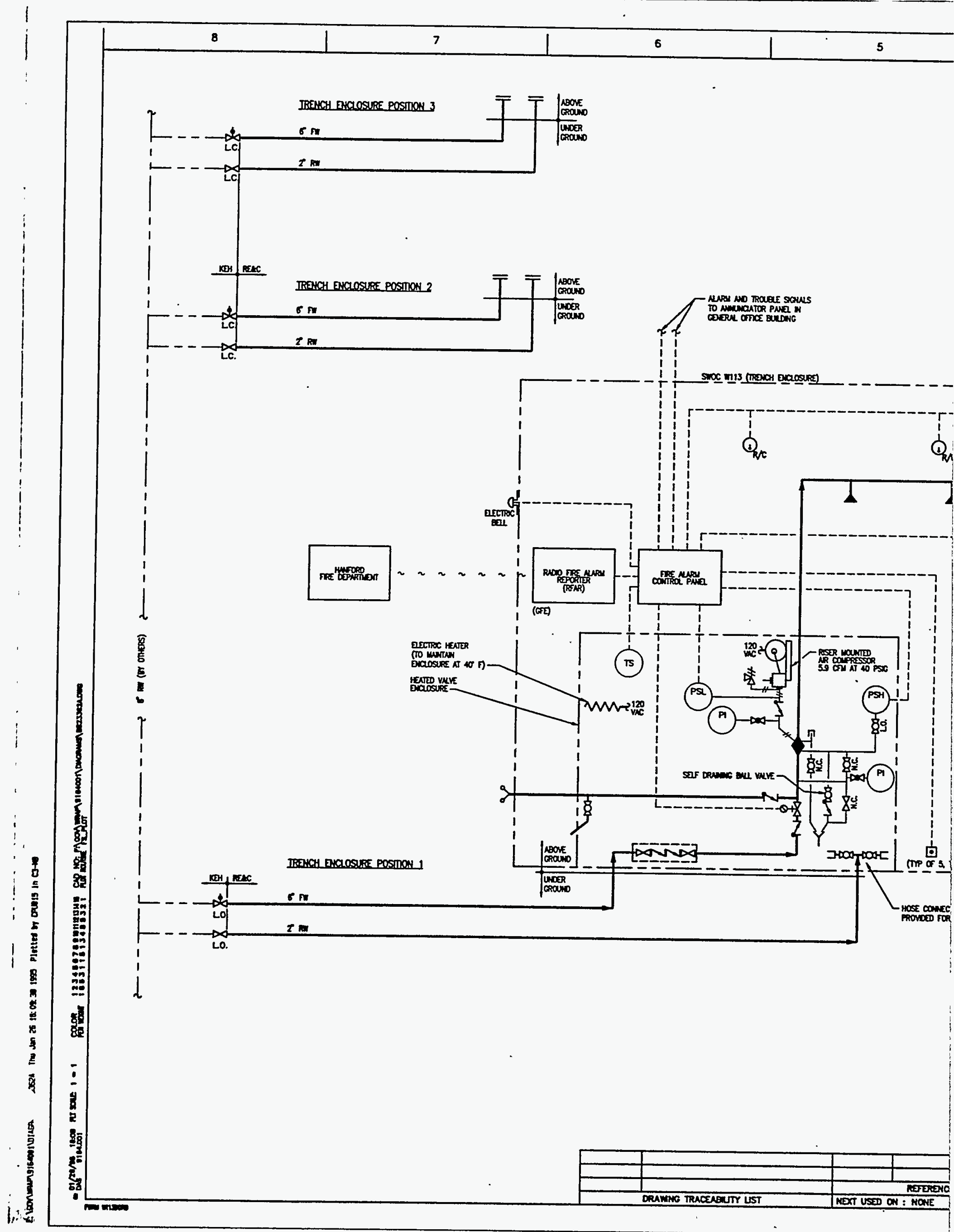




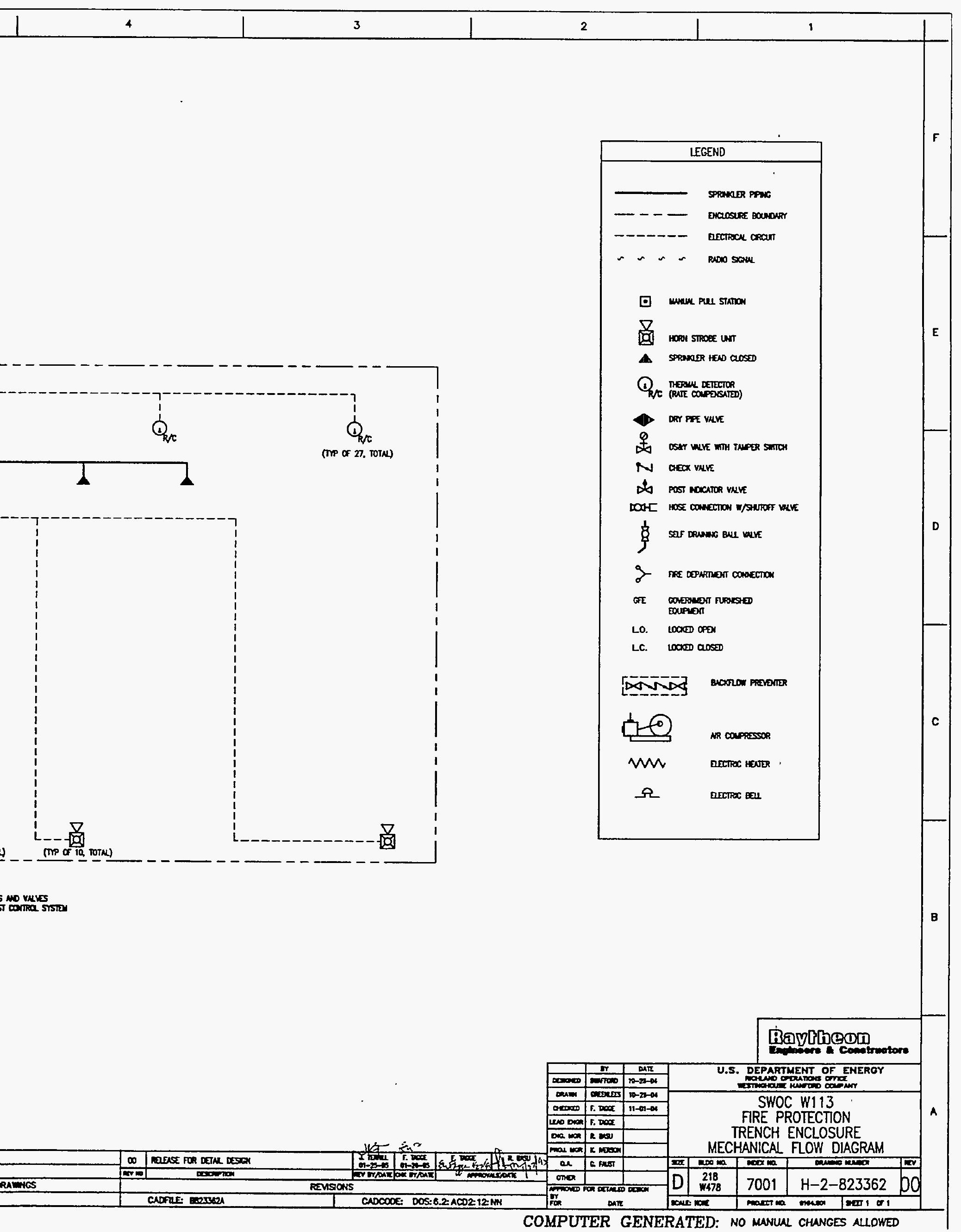




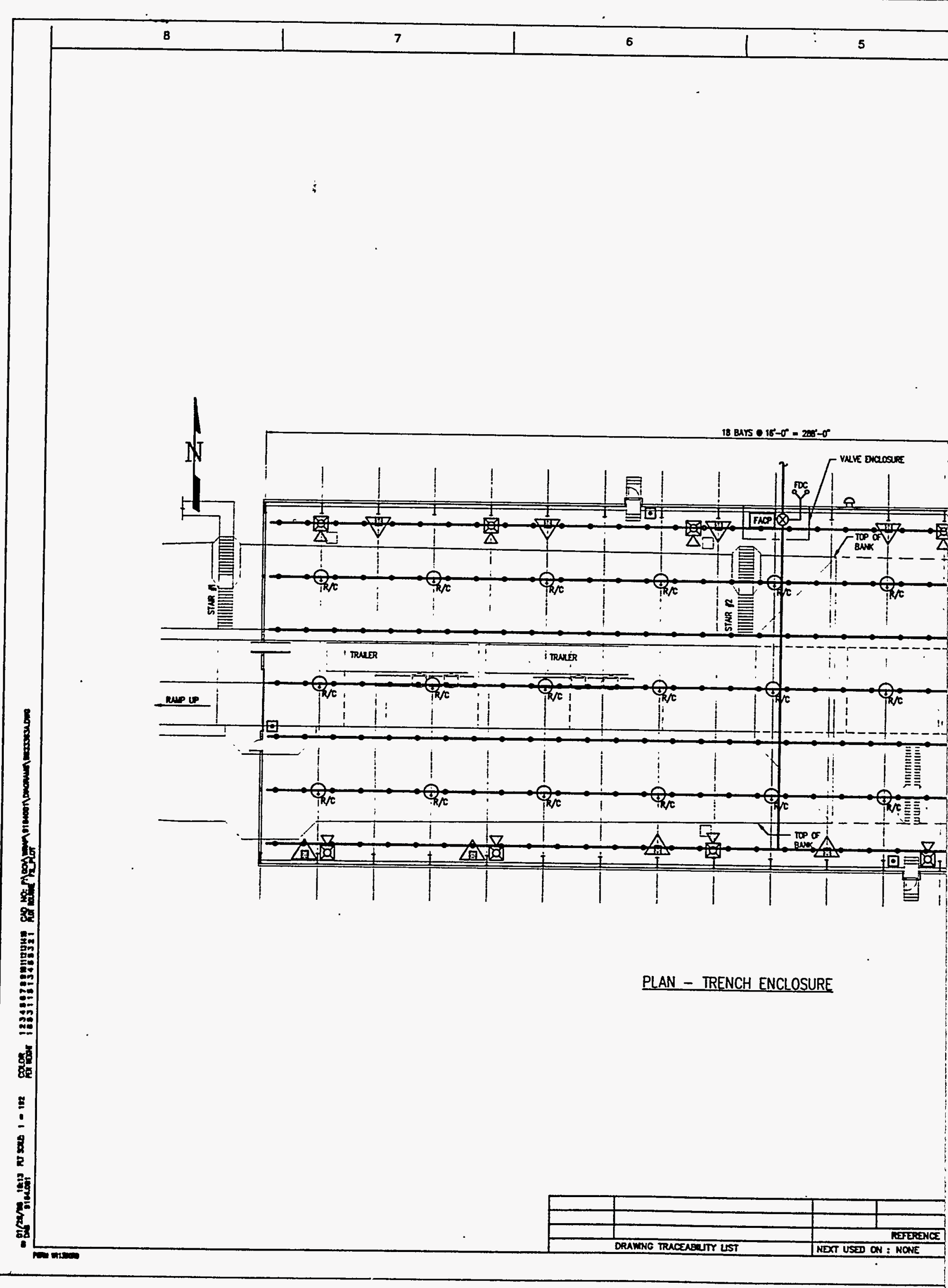




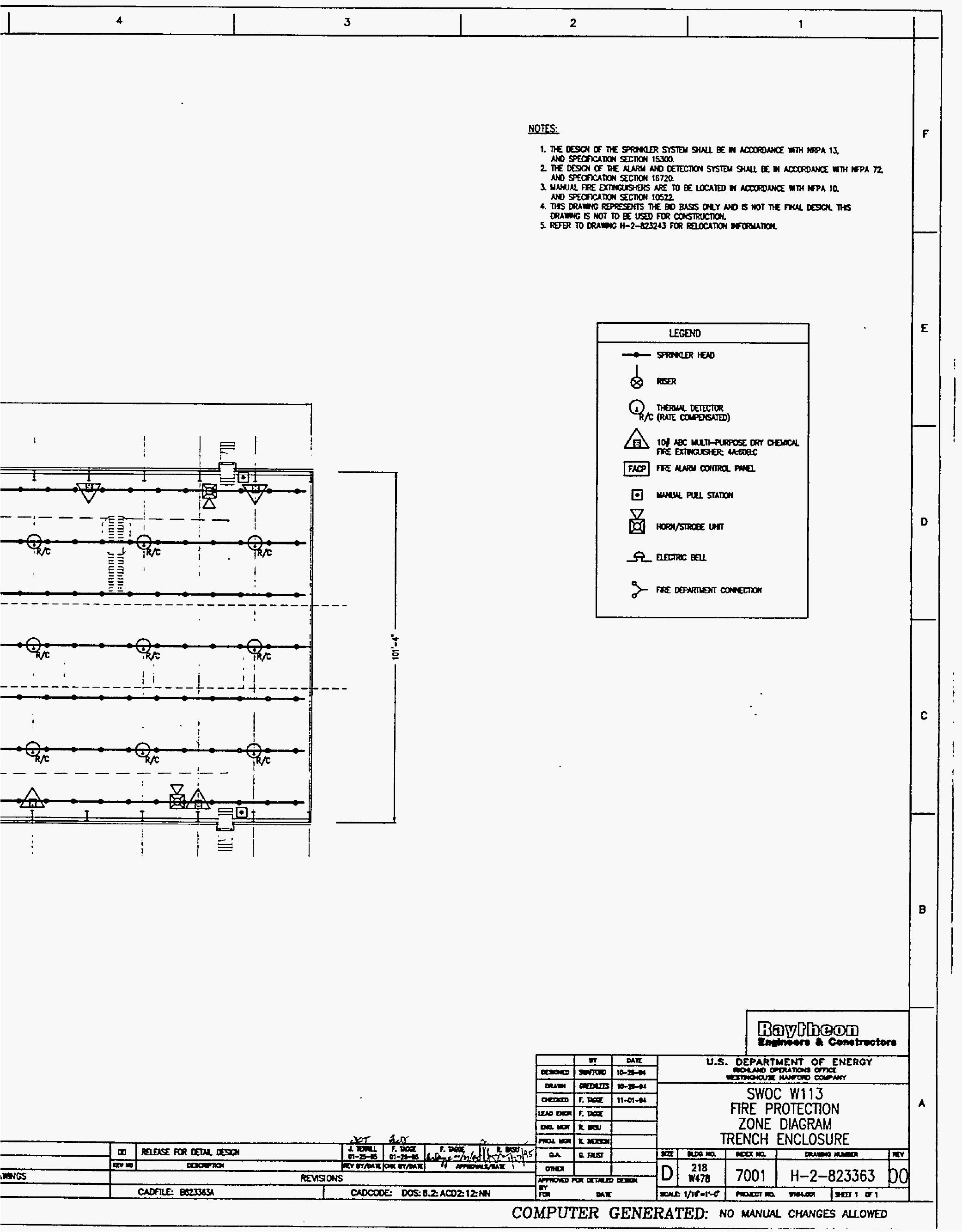




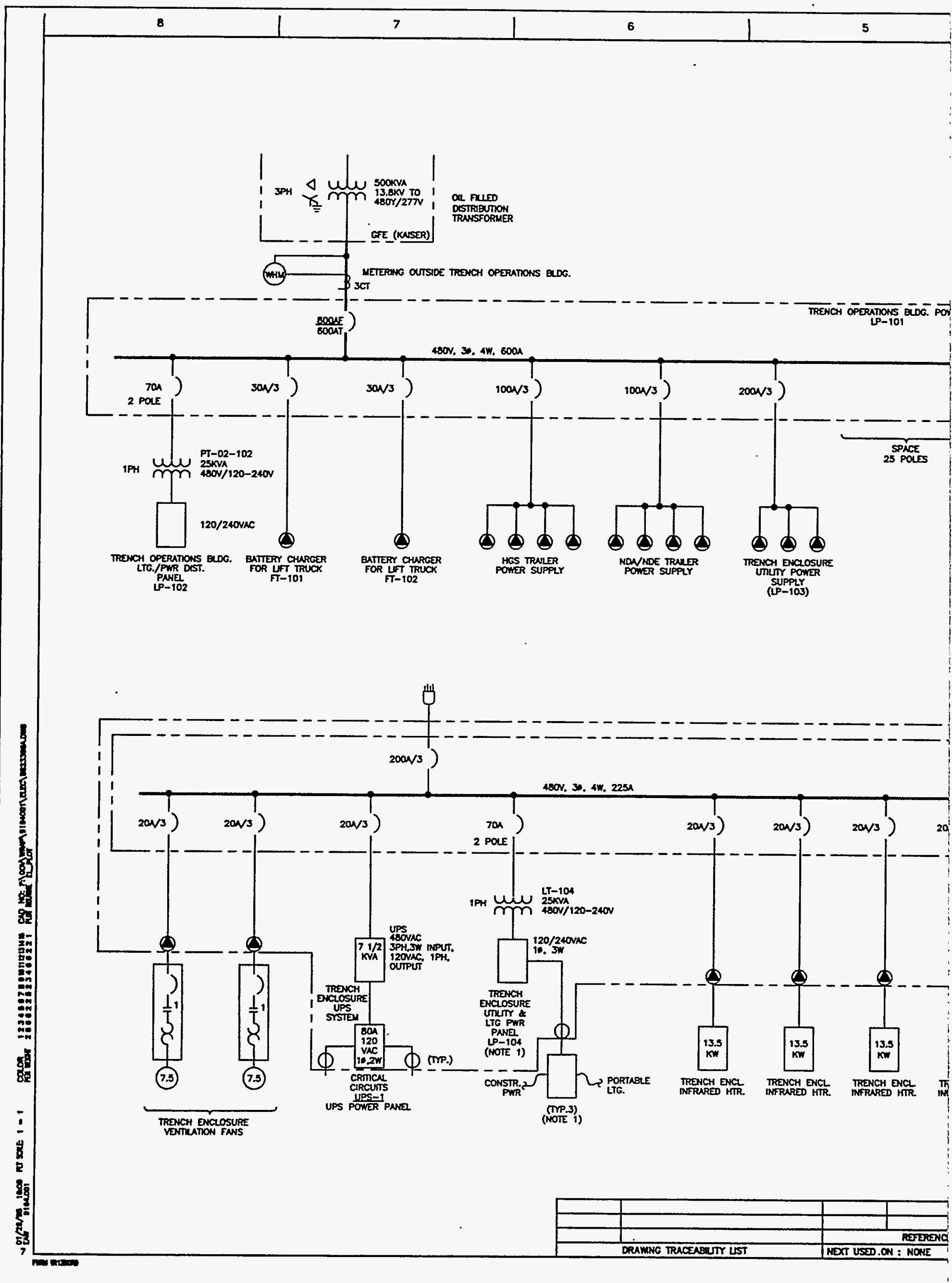




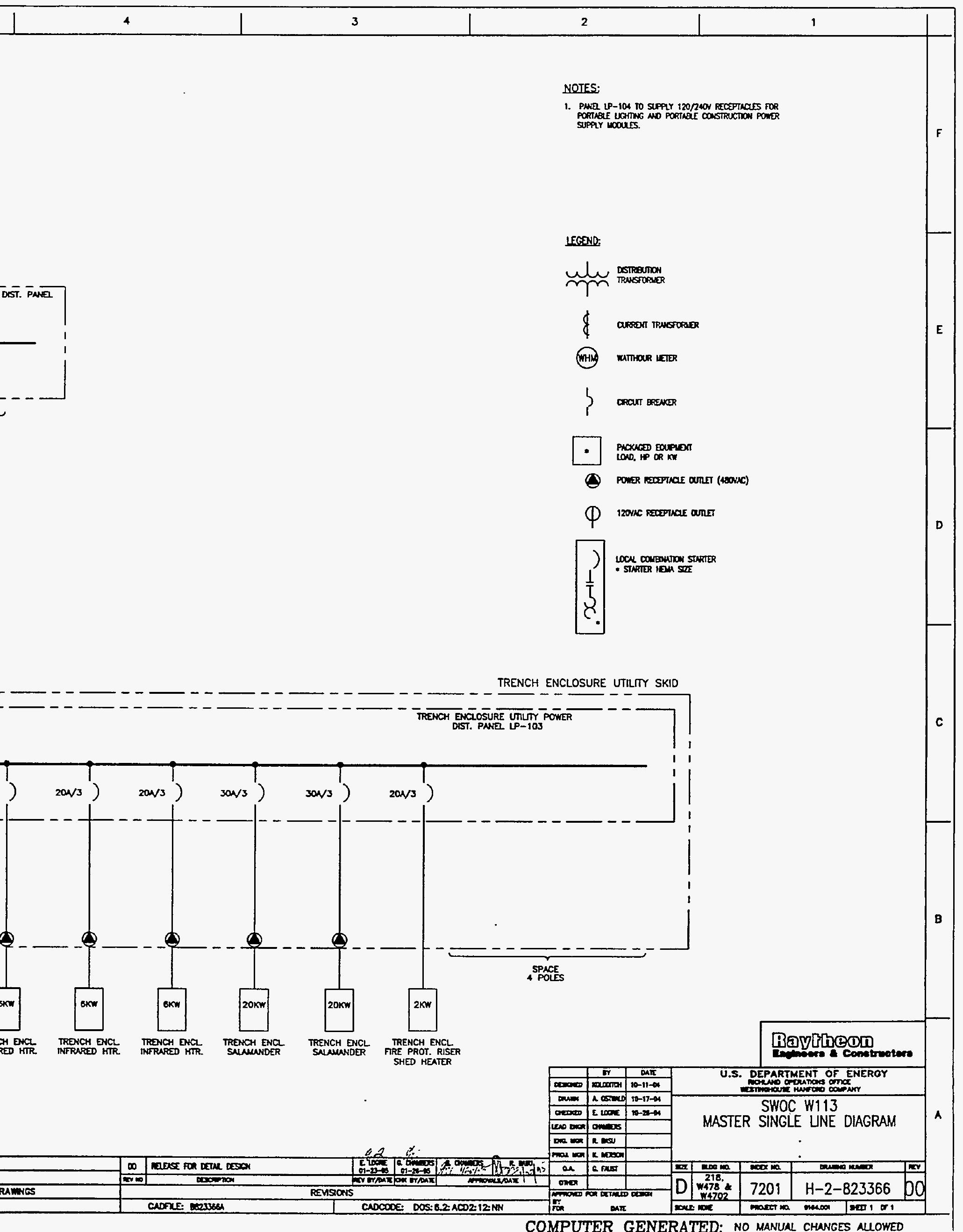




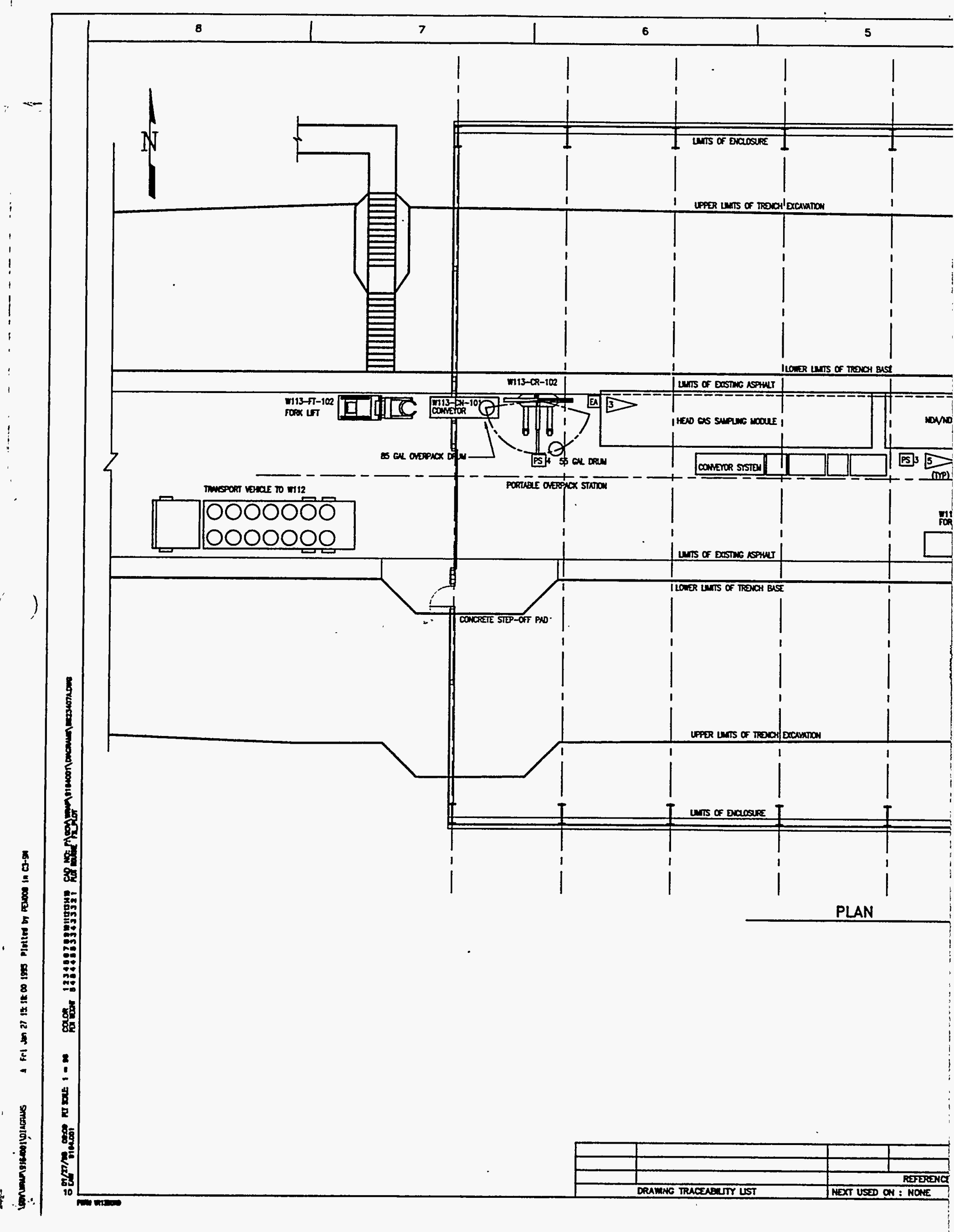


